CUADERNOS DE ESTUDIOS GALLEGOS, LXV Núm. 131 (enero-diciembre 2018), págs. 133-169

ISSN: $0210-847 \mathrm{X}$

https://doi.org/10.3989/ceg.2018.131.05

\title{
PANTÓN COMO EJEMPLO DE LA ORGANIZACIÓN DEL TERRITORIO Y EL POBLAMIENTO EN LA GALICIA MEDIEVAL: \\ LA PARROQUIA, EL COTO, LA ALDEA, EL CASAL Y LA VIVIENDA (SIGLOS XIII-XV)
}

\author{
José Antonio López SABATEL \\ Doctor en Historia
}

ORCID iD: http://orcid.org/0000-0002-5280-0961

Copyright: (C) 2018 CSIC. La edición electrónica de esta revista se distribuye bajo los términos de una licencia de uso y distribución Creative Commons Reconocimiento 4.0 Internacional (CC BY 4.0).

Cómo citar/Citation: José Antonio López SABatel, "Pantón como ejemplo de la organización del territorio y el poblamiento en la Galicia medieval: la parroquia, el coto, la aldea, el casal y la vivienda (siglos XIII-XV)”, Cuadernos de Estudios Gallegos, 65, núm. 131 (2018), págs. 133-169, https://doi.org/10.3989/ceg.2018.131.05 


\section{PANTÓN COMO EJEMPLO DE LA ORGANIZACIÓN DEL TERRITORIO \\ Y POBLAMIENTO EN LA GALICIA MEDIEVAL: LA PARROQUIA, EL COTO, LA ALDEA, EL CASAL Y LA VIVIENDA (SIGLOS XIII-XV)}

\section{RESUMEN}

Este artículo tiene como objetivo llevar a término el análisis de la de la parroquia, el coto, la aldea, el casal y la vivienda como elementos articuladores del hábitat rural medieval en las tierras de Pantón, espacio homogéneo y característico de la Ribeira Sacra lucense. También se han examinado las transformaciones y continuismos de las diferentes entidades de poblamiento y sus efectos sobre el entramado poblacional actual. Para tal fin se ha procedido al escrutinio e inventario de la documentación procedente de las instituciones más representativas de la zona. Además, se ha añadido un soporte heurístico territorial más amplio con el fin de paliar la escasez documental relativa a la alta Edad Media, así como de situar la información extraída concerniente a Pantón dentro de un contexto más extenso y generalizado.

Palabras Clave: Pantón medieval, parroquia, coto, aldea, casal, vivienda.

\section{PANTÓN COMO EXEMPLO DE ORGANIZACIÓN DO TERRITORIO E POBOAMENTO NA GALICIA MEDIEVAL: A PARROQUIA, O COUTO, A ALDEA, O CASAL E A VIVENDA (SÉCULOS XIII-XV)}

RESUMO

Este artigo ten como obxectivo completar a análise da parroquia, o couto, a aldea, o casal e a vivenda como elementos artelladores do hábitat rural medieval das terras de Pantón, espazo homoxéneo e característico da Ribeira Sacra lucense. Tamén se examinaron as transformacións e continuísmos das diferentes entidades de poboación e os seus efectos sobre a rede de poboamento actual. Para tal fin procedeuse ao escrutinio e inventario da documentación procedente das institucións máis representativas da zona: mosteiros de San Vicenzo de Pombeiro, Santa María de Ferreira, San Vicenzo do Pino (Monforte) e catedral de Lugo. Ademais, engadiuse un soporte heurístico territorial máis amplo co fin de paliar a escaseza documental relativa á alta Idade Media, así como de situar a información extraída concernente a Pantón dentro dun contexto máis extenso e xeneralizado.

PALABRAS ClaVe: Pantón medieval, parroquia, couto, aldea, casal, vivenda.

\section{PANTÓN AS AN EXAMPLE OF THE TERRITORIAL AND SETTLEMENT ORGANISATION IN MEDIEVAL GALICIA: THE PARISH, THE COTO, THE VILLAGE, THE MESSUAGE AND THE DWELLING $\left(13^{\mathrm{TH}}-15^{\mathrm{TH}}\right.$ CENTURIES $)$}

\section{ABStRact}

This article aims to complete the analysis of the parish, the "coto", the village, the messuage and the dwelling as assembling elements of the medieval rural environment of the lands of Pantón, an homogeneous and characteristic space of Lugo's Ribeira Sacra. In addition, the transformation and preservation of the different settlements and their effects on the current situation of the population were also discussed. For this purpose, it has been carried out an examination and inventory of the documentation coming from the most representative institutions in the area. Furthermore, a wider territorial heuristic support was added in order to alleviate the lack of documents on the Early Middle Ages, as well as to position the available information related to Pantón within a broader and more generalised context.

KeY words: Medieval Pantón, Parish, “coto”, Village, Messuage, Housing. 
Recibido/Received: 07/06/2016

Aceptado/Accepted: 02/06/2017

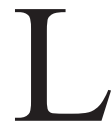

a historiografía siempre ha mostrado gran interés en delimitar y precisar los diferentes núcleos que ordenaron y articularon el territorio y el poblamiento medieval al norte de la península ibérica ${ }^{1}$. En lo que al noroeste peninsular se refiere, recientemente han ido surgiendo diversos estudios monográficos centrados en la ocupación espacial y el hábitat durante esta época histórica; entre estos destacan los realizados para el ámbito berciano por Durany $\mathrm{Castrillo}^{2}$, para el gallego por Sánchez Pardo $^{3}$ y para el portugués por André Evangelista Marques ${ }^{4}$. Enlazando con la tesis presentada por Sánchez Pardo, es importante destacar los progresos relativos al análisis de los datos aportados por los registros materiales que ha experimentado la labor arqueológica durante ya cierto tiempo. Sin embargo, dichas contribuciones encarnan un inconveniente heurístico de primer orden para el presente trabajo, ya que la mayor parte de las excavaciones realizadas hasta la fecha en territorio gallego han tenido por objeto esclarecer posibles continuismos o discontinuidades sufridos por diferentes espacios y hábitats en su transición desde la Antigüedad tardía, pero estableciendo el límite temporal de la investigación en la plena Edad Media, o incluso antes ${ }^{5}$. Sin abandonar este espacio cronológico

\footnotetext{
1 José Ángel García de Cortázar, Del Cantábrico al Duero: trece estudios sobre organización social del espacio en los siglos VIII a XIII, Santander, Universidad de Cantabria, 1999.

2 Mercedes Durany Castrillo, "Organización social del espacio berciano (siglos IX-XIII)", en José Ángel Sesma Muñoz, Carlos Laliena Corbera (coords.), La pervivencia del concepto: nuevas reflexiones sobre la ordenación social del espacio en la Edad Media, Zaragoza, Universidad de Zaragoza, 2008, págs. 149-196.

3 José Carlos SÁnchez Pardo, Territorio y poblamiento en Galicia entre la antigüedad y la plena Edad Media, Santiago de Compostela, Universidade de Santiago de Compostela, 2008.

4 André Evangelista MARQues, Da representação documental à materialidade do espaço. Território da diocese de Braga (séculos IX-XI), Porto, CITCEM, Edições Afrontamento, 2014.

5 María del Carmen Pallares Méndez, José Antonio Puente Mínguez, "Villa Bidualdi. Un despoblado del siglo X. Aproximación arqueológica”, Cuadernos de Estudios Gallegos, 22 (1981), págs. 475-486.

Felipe Criado-Boado, “Arqueología del Paisaje: el área Bocelo-Furelos entre los tiempos paleolíticos y medievales (Campañas de 1987, 1988 y 1989)”, Arqueoloxía/Investigación, 6 (1991), págs. 27-43.

Jorge López Quiroga, Mónica Rodríguez Lovelle, "Dominio político y territorio en Galicia entre la antigüedad y el feudalismo: el alto valle del Támega", en V Congreso de Arqueología Medieval Española: actas: Valladolid, 22 a 27 de marzo de 1999, Valladolid, Junta de Castilla y León, 2001, págs. 733-742. José Manuel Costa García, Emilio Rodríguez Álvarez, David Varela Gómez, "Del complejo militar
} 
(siglos IX-XI), resulta preceptivo mencionar la propuesta metodológica llevada a término por André Evangelista Marques en su estudio sobre territorio de la diócesis de Braga, según la cual, el procedimiento empleado en el análisis de las fuentes se encamina a una mayor comprensión de la realidad material ("la materialidad del espacio") inherente al corpus documental de un territorio considerado más como una abstracción en el que se asienta el ordenamiento social. Los resultados de este escrutinio heurístico transcienden los registros previos de la historiografía portuguesa, al conseguir hacer extrapolable dicho proceso analítico documental a otros objetos materiales de estudio. Puesto que el examen de la organización de un territorio ha de ir más allá de una simple propuesta teórica y metodológica y verse acompañado de un claro interés hacia cuestiones claves como la creación, colonización, estructuración y la configuración social final de un paisaje determinado, no es de extrañar que los espacios temporales elegidos para abordar tales cuestiones se sitúen en épocas de pervivencias y transformaciones que preceden el marco cronológico de este artículo. Adentrándonos ya en los siglos XIII y XV parece cada vez más evidente que la estructura de poblamiento dominante en toda Galicia, al menos desde el siglo XIII, no fue otra que aquella caracterizada por la dispersión y extensión del hábitat gracias a la generalización de los casales ${ }^{6}$.

En lo que concierne a la Ribeira Sacra pleno y bajomedieval, subrayar que de entre los núcleos dotados de naturaleza administrativa y jurisdiccional sobresalieron la parroquia y el coto, mientras que la villa-aldea y el casal fueron los que mejor se perfilaron como agentes estructuradores del hábitat rural. Unidades todas estas que nutren al espacio de estudio de una organización social, económica y política de carácter regional, cuya mayor peculiaridad durante el transcurrir de la Edad Media es la que concierne a su complejidad y a su dinamismo, a su evolución y, en cierto modo, también a su continuismo. Este estudio tiene como cometido el examen de este paisaje social en sus dos vertientes: la originada por el encuadramiento de la población efectuado por el poder y la derivada del hábitat generado por la ocupación del territorio y del trabajo realizado sobre la tierra. Dada la gran extensión e, incluso, indefinición territorial de la Ribeira Sacra y, con el fin de cumplir este objetivo, he decidido acotar el área de estudio al actual municipio de Pantón (Ribeira Sacra lucense). Considero que estas tierras fueron y son el arquetipo exponencial, si no corazón, de lo que fue y aún se define como la Ribeira Sacra campesina. Esta afirmación se apoya en el alcance semántico que se desprende de cada uno de los términos que forman tal enunciado y en su correspondencia con todos y cada uno de los rasgos que personifican dicho espacio:

romano al monacato altomedieval: aproximación a las transformaciones del espacio interior galaico entre los siglos I y IX d. C. a partir de los asentamientos de A Cidadela (Sobrado dos Monxes, A Coruña)", Estrat Crític: Revista d'Arqueologia, 1-2 (2011), págs. 144-155 y 454-464.

6 J. C. SÁnchez PARdo, Territorio y poblamiento..., pág. 346. 


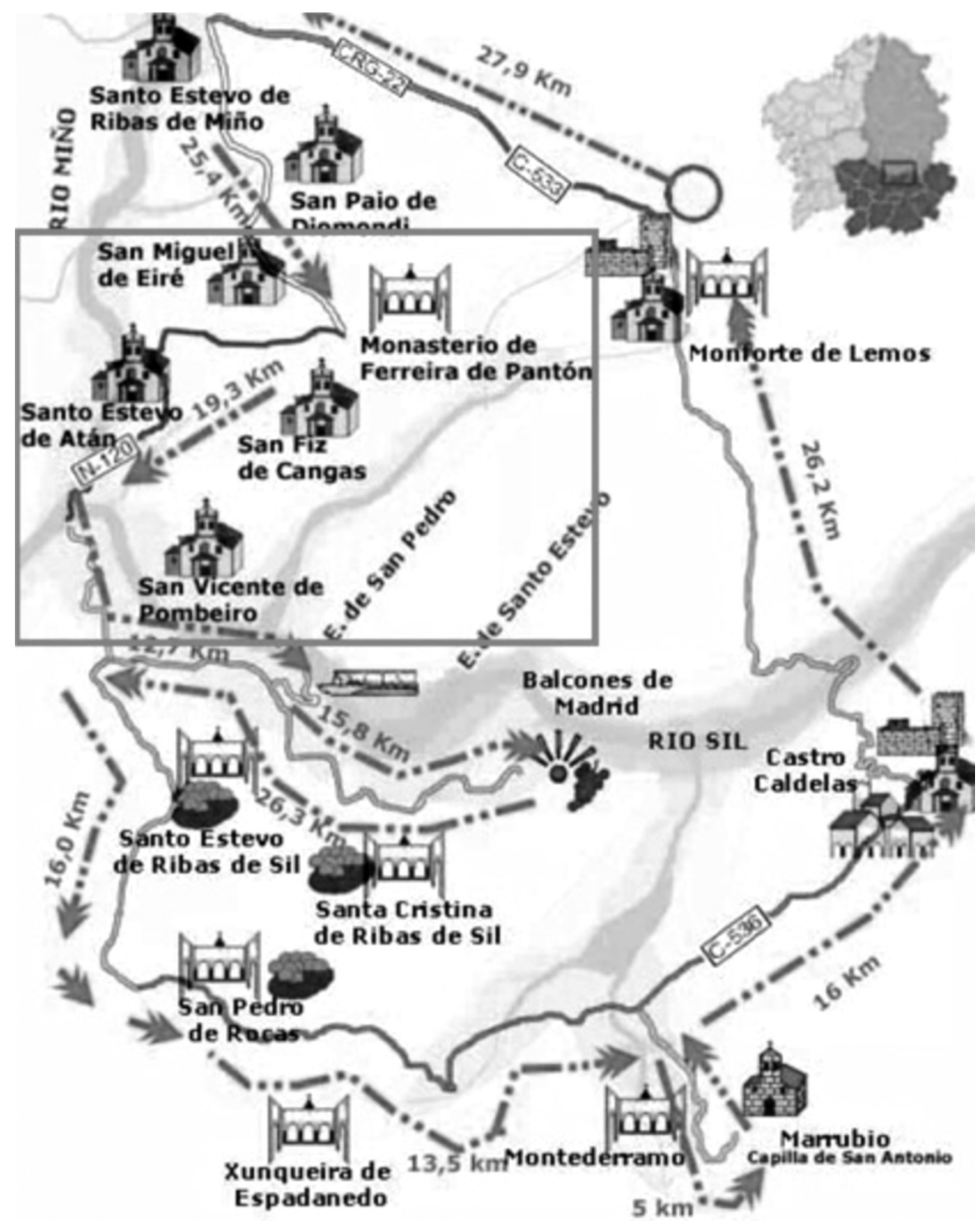

Fig. 1. Principales monasterios conservados en la Ribeira Sacra. Dentro del recuadro, los emplazados en el actual municipio de Pantón. Elaboración propia a partir de la siguiente fuente: IN VINO VIAJAS [en línea], disponible en http://invinoviajas.blogspot.com.es/ [Consulta: 21/03/2017]. 
- Ribeira: área ribereña por naturaleza, se la considera la pequeña Mesopotamia gallega ${ }^{7}$. Las orillas del Miño, del Sil y del Cabe hacen que el ayuntamiento de Pantón muestre unos límites geográficos bien definidos.

- Sacra: de todos los municipios que se puedan integrar en la Ribeira Sacra, es Pantón, seguramente debido a su peculiar topografía, el que contó con más monasterios medievales, cinco $^{8}$. Es por ello por lo que, con el tiempo, se ha convertido en punto de referencia célebre del Románico para los amantes de la historia del arte.

- Campesina: a la ausencia histórica de grandes núcleos urbanos se une la inequívoca e inherente naturaleza agraria de la zona. El continuismo de la vitivinicultura en este territorio se evidencia en dos datos separados por casi 1200 años: el primero se remonta a la carta fundacional de San Esteban de Atán en 816, en la que se registra la primera referencia escrita conocida correspondiente al viñedo 9 ; el segundo proviene de una noticia en prensa de 2014, cuya fuente es un informe del Consejo Regulador de la Ribeira Sacra según el cual el municipio de Pantón, con más de doscientas hectáreas, es el que tiene inscrito mayor número de viñas en este organismo ${ }^{10}$.

Para finalizar con esta breve presentación creo necesario precisar el marco cronológico en el que este trabajo se circunscribe. Si bien es cierto que el grueso de la información sujeta a examen se corresponde con los siglos XIII, XIV y XV, no lo es menos que, con el fin de ofrecer una exposición más coherente, detallada y comprensible de ciertos elementos incluidos en el objeto material de este estudio se hizo inevitable ampliar dicho encuadre temporal al precedente periodo altomedieval. Así pues, fue preciso el escrutinio de aquellos exiguos y, en la mayoría de las ocasiones foráneos testimonios ${ }^{11}$, procedentes de los siglos IX, X, XI y XII, para abordar la formación, devenir y existencia misma tanto de la parroquia como de la aldea desde una perspectiva más global y constante. En consonancia con lo hasta aquí expuesto las fuentes generadoras de los datos sobre los que este artículo se sustenta se pueden dividir en tres grupos claramente diferenciados:

\footnotetext{
7 Xulio Xiz Ramil, "Pantón: a rota interior" en Flora Enríquez Rodríguez (coord.), Pantón. A rota do Románico na Ribeira Sacra, Santiago de Compostela, Agencia Gráfica Gallega, 2002, págs. 139-161 y 143.

8 Santa María de Ferreira, San Vicente de Pombeiro, San Fiz de Cangas, San Esteban de Atán, San Miguel de Eiré.

9 Luis Rodríguez Mínguez, Pantón. Patrimonio y termalismo, Santiago de Compostela, Ribeira Sacra lucense, 2007, pág. 107.

${ }^{10}$ Luis DíAz, La Voz de Galicia/Lemos, 27 de septiembre de 2014.

11 En el sentido de ajenos al ámbito geográfico de este estudio (tierras de Pantón) debido a la escasa presencia de testimonios altomedievales en las colecciones diplomáticas de los monasterios emplazados en este entorno.
} 
Fig. 2. Localización de la Ribeira Sacra en Galicia. Fuente: José MÉndez PÉREZ;

Pablo S. Otero Piñeyro Maseda; Miguel Romaní MARTíneZ, El monasterio de San Salvador de Chantada (siglos XI-XVI): historia y documentos, Santiago de Compostela, CSIC, 2016, pág. 43.
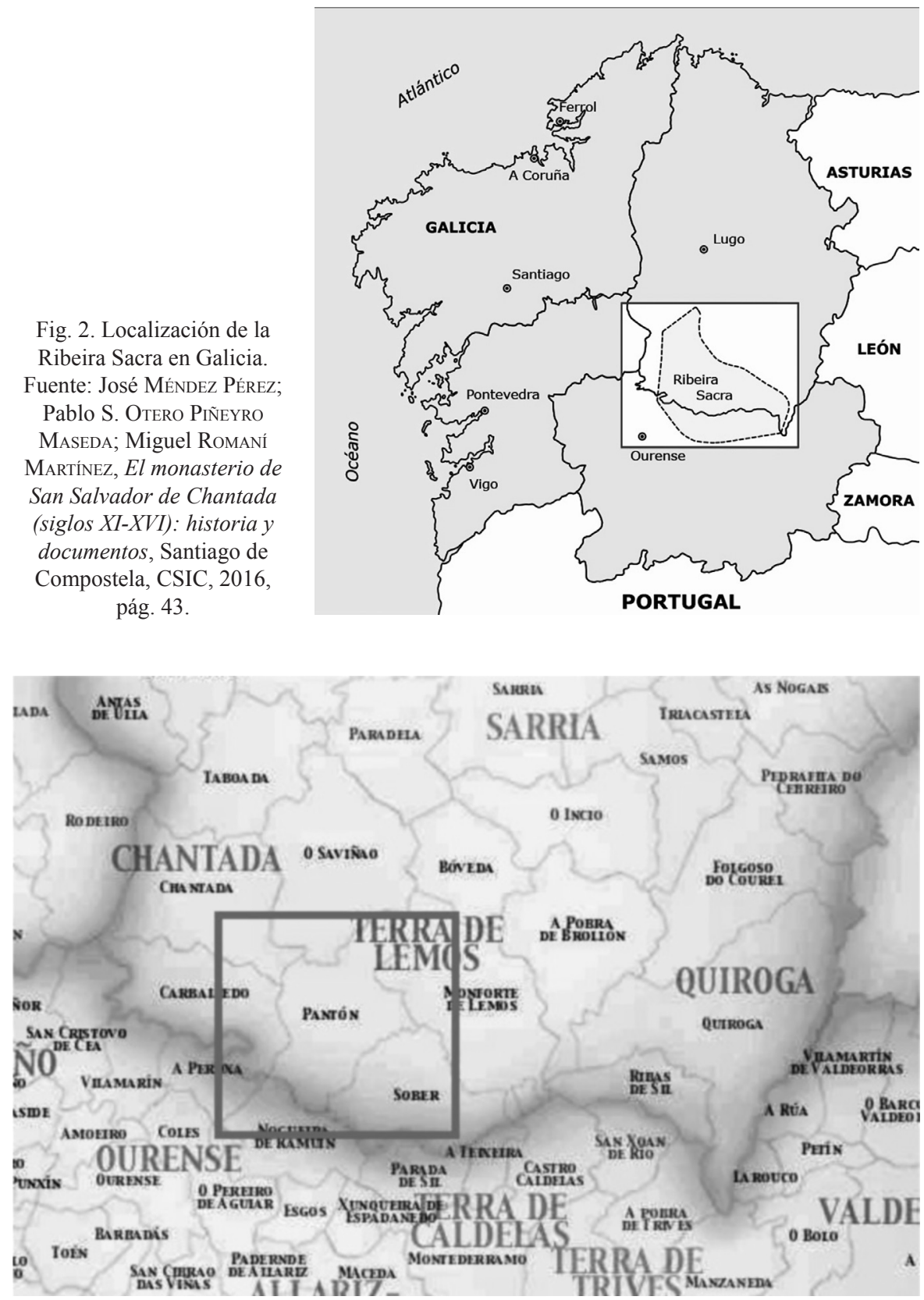

Fig. 3. Localización del municipio de Pantón en la Tierra de Lemos.

Elaboración propia a partir de la siguiente fuente: Concellos y Comarcas De Galicia [en línea], disponible en http://www.gifex.com/ [Consulta: 21/03/2017]. 
- Aquellas emanadas de las instituciones monásticas ubicadas en el territorio que nos ocupa, esto es, los monasterios de San Vicenzo de Pombeiro y de Santa María de Ferreira ${ }^{12}$.

- Aquellas fruto de los diplomas del monasterio de San Vicente de Pino en Monforte y de la catedral de Lugo relativas a emplazamientos sitos en tierras pantonesas ${ }^{13}$.

- Aquellas procedentes de otras instituciones que sirven al doble propósito de sustentar y enriquecer la explicación histórica, al amplificar los marcos espaciales y cronológicos, bien sea, transcendiendo físicamente el actual municipio de Pantón ${ }^{14}$, bien sea, retrotrayéndose al periodo altomedieval ${ }^{15}$.

\section{LA PARROQUIA Y EL COTO}

El fulgor que la parroquia aún proyecta sobre la organización social del espacio en la Galicia rural está fundamentado en su capacidad de integrar un número variable de entidades de población dispersas y dotarlas de férreos lazos de cohesión y de identidad comunitaria. Es notorio cómo la feligresía trascendió

\footnotetext{
${ }_{12}$ Documentación transcrita y publicada en los siguientes volúmenes: Manuel Lucas Álvarez y Pedro Lucas Domínguez, El priorato benedictino de San Vicenzo de Pombeiro y su colección diplomática en la Edad Media, A Coruña, Edicios do Castro, 1996. José Ignacio FernándeZ de VianA y Vieites, Colección diplomática del monasterio de Santa María de Ferreira de Pantón, Lugo, Diputación provincial de Lugo, 1994.

13 Carlos Rodríguez Fernández, La colección diplomática de San Vicente del Pino, Tesis doctoral, Universidad de Granada, Granada, 1991. María Xosé Portela Silva, Documentos da catedral de Lugo. Século XV, Santiago de Compostela, Consello da Cultura Galega, Ponencia de Patrimonio Histórico, 1998. María Xosé Portela Silva, Documentos da catedral de Lugo. Século XIV, Santiago de Compostela, Consello da Cultura Galega, Ponencia de Patrimonio Histórico, 2007.

${ }^{14}$ En este punto me refiero a los monasterios de San Salvador de Asma (Chantada), San Clodio do Ribeiro, Santa María de Oseira y San Pedro de Rocas cuyos fondos se pueden encontrar en: José MÉNDEZ Pérez; Pablo S. Otero Piñeyro Maseda; Miguel Romaní Martínez, El monasterio de San Salvador de Chantada (siglos XI-XVI): historia y documentos, Santiago de Compostela, CSIC, 2016. Manuel LuCAS Álvarez, Pedro Lucas Domínguez, El monasterio de San Clodio do Ribeiro en la Edad Media: estudio y documentos, Sada (A Coruña), Edicios do Castro, 1996. Miguel Romaní MarTínez, et alii, Colección diplomática do mosteiro cisterciense de Sta. María de Oseira (Ourense), Santiago de Compostela, Tórculo Edicións, 1989-2008. Emilio Duro PEÑA, El monasterio de San Pedro de Rocas y su colección documental, Orense, Instituto de Estudios Orensanos "Padre Feijoo", 1972.

15 Para este supuesto, de gran valor fue la documentación procedente de los monasterios de Sobrado de los Monjes y de Celanova. La primera consultada en las siguientes publicaciones: María Carmen Pallares Méndez, El monasterio de Sobrado: un ejemplo de protagonismo monástico en la Galicia medieval, A Coruña, Diputación Provincial de A Coruña, 1975. Pilar Loscertales de GARcía DE VALDeavellano, Tumbos del Monasterio de Sobrado de los Monjes, Madrid, Dirección General del Patrimonio Artístico y Cultural, Archivo Histórico Nacional, 1976. La segunda en: Emilio SÁEz y Carlos SÁEz, Colección diplomática del monasterio de Celanova (842-1230), Alcalá de Henares, Universidad de Alcalá, 1996.
} 
su mera función religiosa en aras de una ancestral y continuada capacidad para articular la vida cotidiana y socioeconómica del mundo rural gallego, desplegando escenarios comunes donde desarrollar y facilitar sentimientos de identificación territorial, además de estrechos vínculos de solidaridad y cooperación campesina. Fiestas, tradiciones, distribución y uso del ocio también encontraron y encuentran cabida en estos términos territoriales, mucho más arraigados en la mentalidad colectiva agraria gallega que aquellos otros de naturaleza más exógena como los municipios ${ }^{16}$. No en vano, la parroquia fue el crisol donde las diferentes existencias campesinas se fundían en la celebración de bautismos, matrimonios y funerales. Estos marcos de ordenación espacial y poblacional sobrevivieron impertérritos a los múltiples cambios generados por la sociedad, gracias a su labor de sostén de un edificio social y religioso en el que los hombres y mujeres nacían, se casaban, envejecían y morían ${ }^{17}$. Un área común que a partir del siglo XIII se consolida en el ámbito utilizado recurrentemente por la documentación medieval gallega para localizar bienes aforados, vendidos, donados o testados, así como para emplazar unidades de habitación y explotación. García de Cortázar, en su papel de precursor a la hora de definir a la organización social del espacio como preocupación historiográfica, ya fijó los tres elementos que dotaron de preeminencia a la parroquia medieval sobre la aldea como escenario prioritario en el que se desenvolvió la sociabilidad de la población: en primer lugar, cabe destacar el edificio de culto en sí mismo; en segundo, un territorio bien delimitado topográficamente en torno al mismo; y, para finalizar, una comunidad humana, al principio de naturaleza religiosa, pero con el tiempo perfectamente definida por sus vínculos económicos, sociales, jurídicos y políticos ${ }^{18}$.

En el periodo que nos ocupa es bien conocido el importante papel que desempeñó la pertenencia a un determinado colectivo humano en la fijación de una conciencia común de identidad, fundamentada no sólo en las redes de parentesco y vínculos vecinales de sus miembros, sino también en las diversas formas de colaboración y asistencia ejercidas por estos con el propósito de superar las necesidades cotidianas. En un tiempo en el que lo individual se subordinaba a lo plural, el individuo era quien era en la medida de su pertenencia a una comunidad, que a la vez de dotarle de seguridad e identidad social le infundía de un sentimiento de filiación respecto a un determinado grupo social y de diferencia-

\footnotetext{
$\overline{16}$ José FARIÑa Tojo, Los asentamientos rurales en Galicia, Madrid, Instituto de Estudios de Administración Local, 1980, pág. 44.

17 Michel Aubrun, La paroise en France, des origines au XVe siècle, París, Picard, 1986, pág. 6.

18 José Ángel García de CORTÁzAR, La Historia rural medieval: un esquema de análisis estructural de sus contenidos a través del ejemplo hispanocristiano, Santander, Universidad de Santander, 1978, págs. 128-129.
} 
ción en relación con otros ${ }^{19}$. Si bien en otras zonas de Galicia fue la aldea, en su función de núcleo articulador de hábitats concentrados o semidispersos, la que integró en un todo a la comunidad campesina, en espacios similares al de este estudio, caracterizados por la proliferación de entidades de población dispersas y aisladas, fue la parroquia la encargada de estructurar el universo rural ${ }^{20}$. La red parroquial, plenamente configurada a partir del siglo $\mathrm{XI}^{21}$, destacó por su pervivencia a través de los siglos, consolidándose de esta manera como la célula básica del poblamiento gallego ${ }^{22}$. La impermeabilidad de estas circunscripciones eclesiásticas a las transformaciones de carácter demográfico y socioeconómico, tan habituales en la Edad Moderna, otorgó al conjunto del entramado parroquial de una estabilidad y continuidad que perduraría hasta nuestros días ${ }^{23}$. De modo que, y a tenor de lo expuesto, no es aventurado considerar a la parroquia como una institución histórica de larga duración ${ }^{24}$.

Esta longevidad nace y se fortalece a partir del siglo XII, con la extensión de entramado de feligresías eclesiásticas gracias a una política de donaciones reales sustentadas en una serie de territorios jurisdiccionales ${ }^{25}$. Siguiendo esta línea de actuación, Alfonso VII cedió en 1139 al monasterio de San Vicente del Pino la jurisdicción de todas las iglesias localizadas en Monforte de Lemos ${ }^{26}$, mientras que su hijo Fernando II haría lo propio otorgando al de Ferreira las cuatro parroquias que conformaron originariamente el coto del mismo nombre ${ }^{27}$. Esta política, obviamente, no se limitó a la Tierra de Lemos, sino que estuvo enmarcada en un proceso que se expandió por toda Galicia ${ }^{28}$ y el norte de Portugal $^{29}$, y que

\footnotetext{
${ }_{19}$ Fernando Martínez GiL, "Religión e identidad urbana en el Arzobispado de Toledo (ss. XVI-XVII)" en Palma Martínez-Burgos García y José Carlos Vizuete Mendoza (coords.), Religiosidad popular y modelos de identidad en España y América, Cuenca, Universidad de Castilla-La Mancha, 2000, págs. 15-57.

${ }^{20}$ Pegerto SaAvedra, Hortensio Sobrado Correa, Antonio Presedo Garazo, "La red parroquial y el clero rural en la Galicia de los siglos XVI-XIX: resultados de una investigación en curso", Obradoiro de historia moderna, 22 (2003), págs. 93-128 y 97.

${ }^{21}$ Fernando López Alsina, "Da protoparroquia ou parroquia antiga altomedieval á parroquia clásica en Galicia” en Fernando García Pazos (coord.), A parroquia en Galicia. Pasado, presente e futuro, Santiago de Compostela, Xunta de Galicia, 2009, págs. 57-76 y 75.

${ }^{22}$ Xosé María Souto GonzÁlez, "Encol do habitat e do poboamento: o caso de Galicia", Cuadernos de Estudios Gallegos, 98 (1982), págs. 7-63.

${ }^{23}$ Pegerto SAAVEdRA, "A rede parroquial desde finais do século XV a mediados do XIX” en F. García Pazos (coord.), A parroquia..., págs. 77-104 y 84.

${ }^{24}$ F. López Alsina, "Da protoparroquia..., pág. 75.

25 José Miguel Andrade Cernadas, El monacato benedictino y la sociedad de la Galicia medieval (siglos X al XIII), Sada (A Coruña), Edicios do Castro, 1997, págs. 212-213.

26 AHN, sección clero, libro 6385, folio 1, pág. 13.

27 J. I. Fernández de Viana y Vieites, Colección diplomática ..., doc. 8, pág. 25.

${ }^{28}$ Fernando López Alsina, La ciudad de Santiago de Compostela en la Alta Edad Media, Santiago de Compostela, Universidad de Santiago de Compostela, 1988, pág. 174.

${ }^{29}$ Luis Carlos Amaral, Formação e desenvolvimento do domínio da diocese de Braga no período da Reconquista (século IX-1137), Oporto, Universidad de Oporto, 2007, pág. 251.
} 


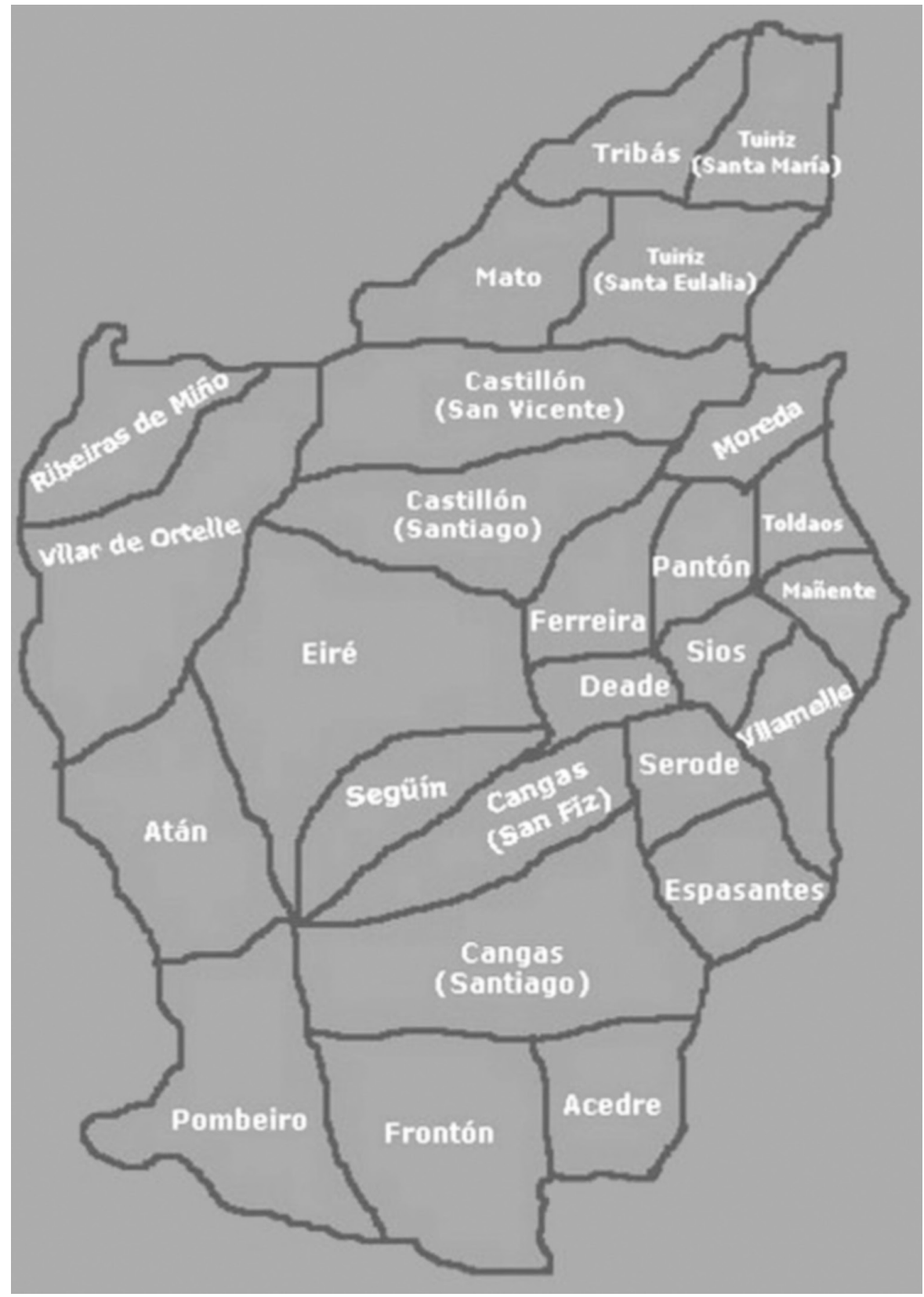

Fig. 4. Red parroquial del municipio de Pantón. Fuente: El rincón de Marga y Fer [en línea], disponible en https://fervatasil.wordpress.com/ [Consulta: 21/03/2017]. 
culminaría en el siglo XIV con la consolidación de una organización parroquial que permanece plenamente reconocible en la actualidad ${ }^{30}$.

Así, de las veintiséis parroquias que configuran el actual municipio de Pantón ${ }^{31}$, veinticuatro de ellas ya encontraron su lugar en los fondos medievales de Ferreira, Pombeiro y San Vicente de Pino, quedando solamente las de Frontón y Següín excluidas de cualquier registro escrito. Esta última seguramente debido tanto a su escaso número de entidades de población, como a la posibilidad de que por aquel entonces estuviese incorporada a la limítrofe parroquia de San Xian de Eiré 32$^{32}$ mientras que en el caso de Frontón tal circunstancia se explicaría por la pertenencia de la misma al coto Pombeiro, según se desprende de la precisa demarcación física que se da del mismo en la concesión regia a dicho monasterio por parte de Alfonso VII ${ }^{33}$.

Si bien la parroquia cumplió un papel transcendental en la articulación del hábitat medieval gallego, no se puede entender su verdadera naturaleza sin tener en consideración los cambios estructurales a escala local originados por la gradual implantación de las diversas prerrogativas señoriales, que tras unos primeros siglos embrionarios, alcanzaron su cénit en el periodo plenomedieval ${ }^{34}$. Una de estas transformaciones se refiere a la entrada en escena de los cotos, unos espacios estrechamente ligados a atribuciones jurisdiccionales y a la colonización eclesiástica, que fueron utilizados ampliamente para precisar geográficamente el territorio parroquial por medio de conocidos accidentes geográficos o elementos históricos ${ }^{35}$. Emplazamientos, todos ellos, que originariamente también fueron empleados para delimitar las superficies acotadas y de este modo fijar el máximo alcance físico de jurisdicciones civiles y criminales ${ }^{36}$. El coto, como primigenio centro neurálgico del poder señorial, reunió una serie de rasgos característicos

\footnotetext{
30 José Carlos SÁnchez Pardo, "Las iglesias rurales y su papel en la articulación territorial de la Galicia medieval (ss. VI-XII): un caso de estudio", Melanges de la Casa de Velázquez, 40 (2010), págs. 149-170 y 161.

${ }^{31}$ Estas son las que siguen: Acedre, Atán, Cangas (San Fiz de Cangas), Cangas (Santiago de Cangas), Castillón (Santiago de Castillón), Castillón (San Vicente de Castillón), Deade, Eiré (San Miguel de Eiré y San Xian de Eiré), Espasantes, Ferreira, Frontón, Mañente, Mato, Moreda (San Román de Moreda), Panton, Pombeiro, Ribeiras de Miño, Següín, Serode, Siós, Toldaos, Tribás, Tuiriz (Santa Eulalia de Tuiriz), Tuiriz (Santa María de Tuiriz), Vilamelle y Vilar de Ortelle.

32 Así al menos queda explícito en el catastro de Ensenada: Archivo General de Simancas, Dirección General de Rentas, $1^{\mathrm{a}}$ Remesa, Catastro de Ensenada, Respuestas Generales, Libro 186, Imagen 465.

${ }_{33}$ M. Lucas Álvarez, P. Lucas Domínguez, El priorato benedictino..., doc. 7, pág. 61.

34 Amancio Isla Fernández, La sociedad gallega en la alta Edad Media, Madrid, CSIC, 1992, pág. 255.

35 J. C. SÁnchez PARdo, "Las iglesias...", págs. 165-166.

36 José Avelino Gutiérrez GonzÁlez, "Procesos de transformación del poblamiento antiguo al medieval en el norte peninsular astur" en Beatriz Arízaga Bolumburu et alii, Mundos medievales. Espacios, sociedades y poder: homenaje al profesor José Ángel García de Cortázar y Ruiz de Aguirre, Santander, Universidad de Cantabria, 2012, vol. 1, págs. 599-614 y 604.
} 
dignos de destacar. El primero de ellos, relativo a su extensión, es partícipe de una tendencia continuista común en la alta Edad Media: del mismo modo que el condado, como nuevo centro administrativo, se circunscribió mayoritariamente al antiguo trazado comarcal o Territoria preexistente ${ }^{37}$, y la actual red parroquial hizo lo propio con las antiguas villae $e^{38}$; muchas feligresías e incluso municipios del presente no son más que prolongaciones temporales, en cuanto a sus dimensiones, de los antiguos cotos monásticos ${ }^{39}$.

La fisonomía de los cotos no difirió del modelo clásico de explotación señorial habitual a lo largo de la Edad Media, conservando un núcleo donde el cenobio ocupó la posición predominante, junto con las pertinentes edificaciones para el almacenamiento y transformación de los diferentes productos, y los terrenos agrícolas y forestales orientados a cubrir las inmediatas necesidades de los monjes ${ }^{40}$. Al margen de este espacio rector se hallaban las diversas unidades de hábitat y explotación, ya fuesen éstas villas, casales o simples heredades, sobre las que recayeron los derechos dominicales y jurisdiccionales del monasterio. Un claro ejemplo de continuidad del hábitat hasta nuestros tiempos es reconocible en el antiguo coto de Pombeiro, en el que se documentan veinte de las veinticinco entidades de población existentes en la actualidad: dieciséis de ellas documentadas en la colección diplomática del monasterio de San Vicente ${ }^{41}$ y otras cuatro en los fondos correspondientes al de Ferreira ${ }^{42}$.

En relación al número de campesinos que habitaban los cotos bajo la férula señorial, este estudio no tiene como objetivo abordar un análisis demográficocuantitativo puesto que para tal fin, y no es ninguna novedad, se hace necesario

\footnotetext{
37 Anselmo López Carreira (ed.), O Condado de Lemos na Idade Media. I Simposio de Historia en Terra de Lemos, Ourense, Xunta de Galicia, 2008, pág. 21.

38 María Carmen Pallares, Ermelindo Portela, "El lugar de los campesinos. De repobladores a repoblados" en Ana Rodríguez (ed.), El lugar del campesino en torno a la obra de Reyna Pastor, Valencia, CSIC, 2007, pág. 66.

${ }^{39}$ Este último particular (la estrecha identificación física entre coto medieval y los actuales términos municipales) se evidencia en las coincidentes demarcaciones jurisdiccionales de los cuatro monasterios más próximos a la orilla izquierda del Sil, esto es, San Esteban (Nogueira de Ramuín), Santa Cristina (Parada de Sil), Rocas (Esgos) y Xunqueira de Espadañedo (municipio del mismo nombre): Emilio Duro Peña, El monasterio de San Esteban de Ribas de Sil, Orense, Instituto de Estudios Orensanos "Padre Feijoo", 1977, pág. 218. Victor Rodríguez MuÑz, O Mosteiro de Santa Cristina de Ribas de Sil na Idade Media, Ourense, Museo Arqueolóxico Provincial de Ourense, 2010, pág. 50. E. Duro PeÑa, El monasterio de San Pedro..., pág. 41. Sara Pereira Ferreiro, "El monasterio de Santa María de Xunqueira de Espadañedo y su colección diplomática”, Boletín Auriense, 9 (1979), págs. 151-230 y 158.

${ }^{40}$ María Carmen Pallares, Ermelindo Portela, El Bajo Valle del Miño en los siglos XII y XIII. Economía agraria y estructura social, Santiago de Compostela, Universidad de Santiago, 1971, págs. 108-110.

${ }^{41}$ Estas unidades de poblamiento son las que siguen: Amandi, Barrio, Bazal, Cibrisqueiros, Manción, Moredo, Outeiro, Penaveada, Piúca, A Presa, Ribas de Sil, San Pedro, Souto, Torre, Touza y Vilamirón.

${ }^{42}$ Barrio, Cascaxide, O Regueiro y San Cosmede.
} 
tomar el pulso a unas fuentes preestadísticas que en el mejor de los casos ofrecen una escasa e imprecisa información sobre población y poblamiento ${ }^{43}$, y en el peor incluso mienten ${ }^{44}$. Sin embargo, en raras ocasiones, y principalmente en áreas que exceden el marco geográfico preestablecido, la fortuna toma la forma de un puntual interés por parte de priores y abades por facilitar una relación de moradores en sus cotos, bien sea para asegurarse ante notario la fidelidad de sus vasallos o bien con el fin de reafirmar sus prerrogativas forales. Respecto al primer caso, en un documento fechado en $1282^{45}$ los moradores del coto de Lebosende ${ }^{46}$ manifiestan públicamente su vasallaje respecto al monasterio de San Clodio do Ribeiro. Estamos ante cuarenta hombres y una única mujer (probablemente viuda); aplicando los porcentajes de nupcialidad y natalidad que señalan Lucas Álvarez y Lucas Domínguez durante este periodo para el resto del área de influencia de dicho monasterio ${ }^{47}$, los casados serían de 35 a $36^{48}$, contando con sus mujeres de 70 a 72 individuos que, a su vez tendrían, de 50 a 51 hijos $^{49}$, es decir de 120 a 123 sujetos repartidos en los diversos matrimonios, que sumados al resto de solteros (de cinco a seis personas), compondrían una población estimada de entre 126 y 128 habitantes. El segundo supuesto, datado en $1357^{50}$, hace referencia al coto de Ambasmestas y Oleiros ${ }^{51}$; se trata de un texto mediante el cual el abad del monasterio de Oseira detalla los vecinos de este territorio, que suman nueve matrimonios, uno de ellos con un hermano y dos mujeres con sendos hijos, de forma que, por muy benignos y optimistas que fuesen los coeficientes concedidos en razón del número de hijos por cada matrimonio, se pone de manifiesto la evolución poblacional gallega, tiempo atrás señalada por García Álvarez, caracterizada por un gran periodo de crecimiento hasta 1280 para descender progresivamente hacia al gran colapso propio de mediados del siglo XIV ${ }^{52}$.

\footnotetext{
43 Ángel Barrios García, Alberto Martín ExPósito, "Demografía medieval: modelos de poblamiento en la Extremadura castellana a mediados del siglo XIII”, Studia histórica. Historia medieval, 1 (1983), págs. $113-148$ y 116.

${ }^{44}$ José Antonio Salas Auséns, "Cuando las fuentes nos engañan: fogajes, vecindarios y demografía (ss. XIV-XVIII)”, Aragón en la Edad Media, 20 (2008), págs. 691-708.

45 M. Lucas Álvarez, P. Lucas Domínguez, El monasterio de ..., doc. 195, pág. 391.

46 Actual parroquia del mismo nombre en el municipio de Leiro, Ourense.

${ }^{47}$ M. Lucas Álvarez, P. Lucas Domínguez, El monasterio de ..., págs. 70 y 72.

${ }^{48}$ Un $89 \%$ de los cuarenta hombres.

49 Una fertilidad de 1,42 hijos por matrimonio.

${ }^{50}$ M. Romaní Martínez, et alii, Colección diplomática do..., vol. 3, doc. 1734, págs. 264-265.

${ }^{51}$ En la actualidad la parroquia se denomina Oleiros, siendo Ambasmestas un lugar dentro de la misma en el municipio de Carballedo en la provincia de Lugo.

${ }^{52}$ Manuel Rubén García Álvarez, Galicia y los gallegos en la Alta Edad Media. Demografía 1, Santiago de Compostela, Pico Sacro, 1975, pág. 282.
} 


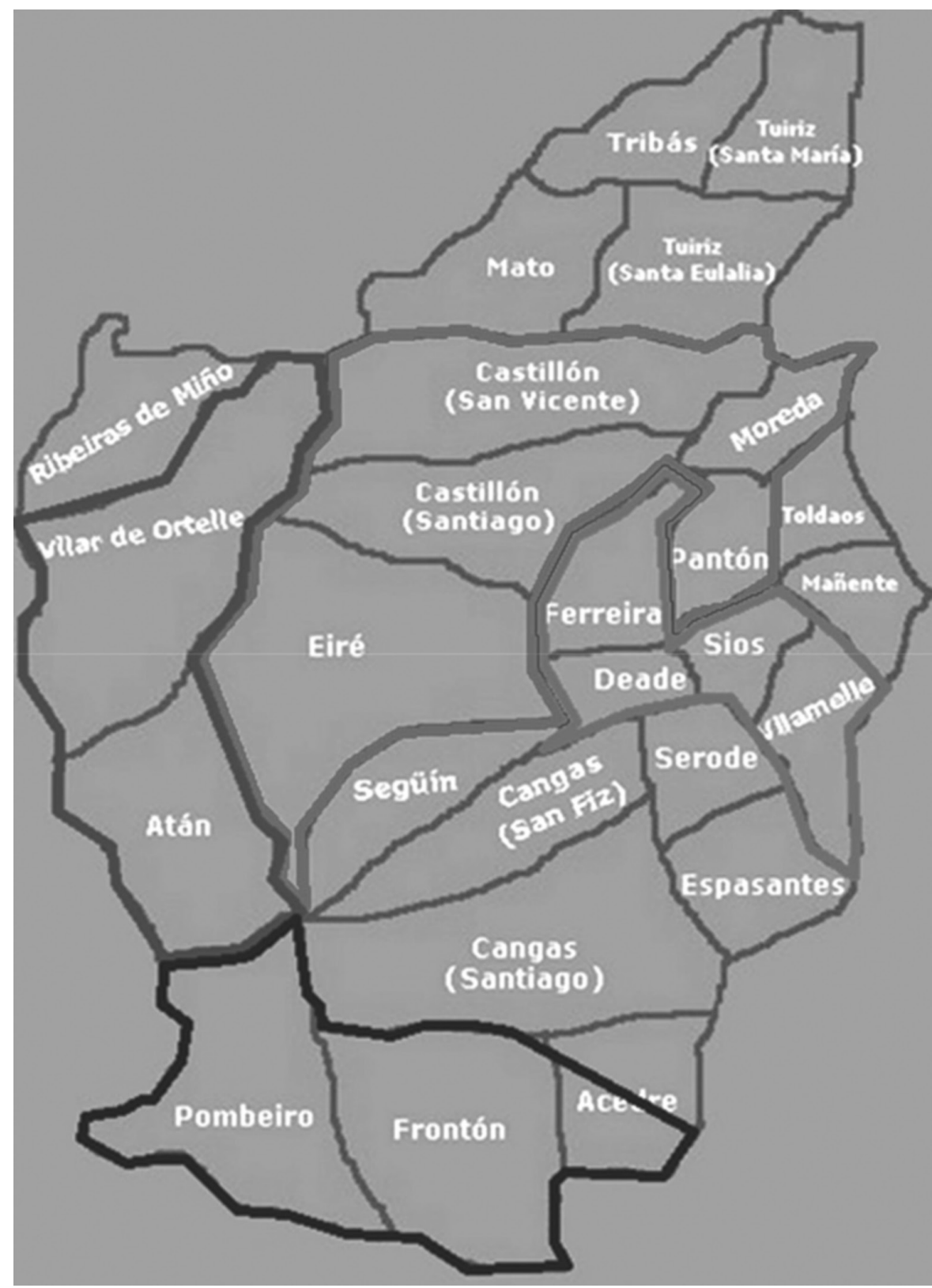

Fig. 5. Cotos en Pantón: en verde, el coto de Ferreira; en rojo, los cotos de Pantón, Eiré, Los Castillones y Moreda; en morado, los cotos de Vilar de Ortelle y Atán; en azul, el coto de Pombeiro. Elaboración propia a partir de la siguiente fuente: El rincón de Marga y Fer [en línea], disponible en https://fervatasil.wordpress.com/ [Consulta: 21/03/2017]. 
Los únicos datos mínimamente adecuados con los que intentar formular un más que limitado enunciado demográfico concerniente a un coto circunscrito al actual municipio de Pantón surgen de la relación de moradores del coto de Atán en 1372, que se encuentra en la documentación de la catedral de Lugo. Se enumeran diecinueve individuos, tres de ellos clérigos, y el resto cabezas de grupos domésticos. Multiplicando estas unidades familiares por el coeficiente del 4,72 atribuido al partido de Monforte ${ }^{53}$, se obtendría una población para el coto de Atán en este año de entre 75 y 80 individuos.

El territorio que ocupa el actual municipio de Pantón contó con ocho cotos: Ferreira, Pantón, Los Castillones, Eiré, Moreda, Vilar de Ortelle, Atán y Pombeiro. El primero de ellos comprendió las actuales parroquias de Ferreira, Deade, Siós y Vilamelle, y aparece por primera vez en la documentación en 1180, a modo de concesión regia hacia el monasterio de Ferreira por parte de Fernando II ${ }^{54}$. Este coto quedó bajo la custodia de los abades cistercienses de Meira, hasta que en 1263 fue cedido en encomienda a Andrés Fernández de Castro, señor de Lemos y Sarria $^{55}$. Es a partir de este instante cuando el coto de Ferreira quedó plenamente vinculado a los cotos de Pantón en $1346^{56}$, y a los de Eiré, Moreda y Los Castillones en $1435^{57}$, todos ellos bajo la jurisdicción de los tenentes y condes de Lemos y con demarcaciones que coincidieron con las de las parroquias actuales del mismo nombre. Circunstancia esta última también válida para los cotos de Vilar de Ortelle y Atán, ambos bajo la jurisdicción del obispo de Lugo; el primero fue adquirido en 1369, tras una permuta de posesiones con la priora del monasterio de Santa María a Nova ${ }^{58}$, y el segundo en 841 al ser donado por Alfonso II $^{59}$; la última ocasión en la que se documenta es en 1372, a raíz de un acuerdo alcanzado por el obispado con los moradores de dicho coto para zanjar la disputa existente entre las partes por diversas posesiones ${ }^{60}$. Esta concordancia entre parroquia y coto no afectó en modo alguno a la delimitación del coto de Pombeiro realizada por Alfonso VII ya que, según los lindes trazados en aquella ocasión, se extendería

\footnotetext{
${ }^{53}$ Reyna Pastor (coord.), Poder monástico y grupos domésticos en la Galicia foral (siglos XIII-XV). La casa. La comunidad, Madrid, CSIC, 1990, pág. 219 (nota 1).

54 J.I. Fernández de Viana y Vieites, Colección diplomática del..., doc. 8, pág. 25.

55 Ibid., doc. 20, pág. 34.

56 Ibíd., doc. 49, pág. 65.

57 Ibid., doc. 167, pág. 207.

${ }_{58}$ María Xosé Portela Silva, Documentos da catedral..., vol. 2, doc. 708, pág. 827.

59 Luis SÁnchez Belda, Documentos reales de la Edad Media referentes a Galicia, Servicio de publicaciones del ministerio de educación nacional, Madrid, 1953, doc. 8, pág. 27. Documento falso o copiado del original según se sigan las interpretaciones de Barrau-Dihigo o Sánchez Albornoz respectivamente. Ver Louis Barrau-Dihigo, "Etude sur les actes des rois asturiens (718-910)", Revue Hispanique, 46 (1919), pág. 4. y Claudio Sánchez Albornoz, Despoblación y repoblación del valle del Duero, Buenos Aires, Instituto de Historia de España, 1966, págs. 13-19.

${ }^{60}$ M. X. Portela Silva, Documentos da catedral..., vol. 2, doc. 725, págs. 848-849.
} 
por las feligresías de Pombeiro, Frontón y por la parte más meridional de la de Acedre $^{61}$. El coto de Pombeiro compartiría el mismo destino que el de Ferreira, al entregarse en encomienda en 1383 al conde de Lemos, Pedro Enríquez de Castro $^{62}$, en consonancia con un proceso generalizado en Galicia desde mediados del siglo XIII, por el cual los cotos primero se encomiendan y luego se aforan a una nobleza local, que con el tiempo pretende adquirir el condominio de los mismos o incluso su plena propiedad ${ }^{63}$.

\section{EL HÁBITAT ALDEANO}

Quien esté familiarizado con el poblamiento rural gallego sin duda es consciente de su extrema complejidad, no sólo en lo concerniente a su morfología, sino también en lo relativo a su ordenación. Una extensa variedad estructural que ha ido pareja de un verdadero laberinto terminológico nacido de aquellos que se han aventurado a formalizar una clasificación y ordenación de los diferentes modelos y tipologías concernientes al hábitat. Se podría empezar por la carencia de una clara conformidad a la hora de fijar unánimemente la célula básica del poblamiento gallego, ya que si bien es cierto que la aldea pareció recibir tal honor por parte de muchos geógrafos, algunos de sus colegas decidieron inclinarse por otras opciones como la casa, el lugar, el casal o la parroquia ${ }^{64}$. Menos aún imperó el consenso cuando le llegó el turno a la clasificación tipológica de la aldea, sobresaliendo entre los diversos modelos los planteados por Fariña Tojo y Bouhier ${ }^{65}$. Misma falta de conformidad protagonizó asimismo la (in)definición de la estructura del poblamiento según los nebulosos estadios de concentración o dispersión característicos del mismo ${ }^{66}$. Toda esta maraña de puntos de vista contrapuestos,

\footnotetext{
$\overline{{ }_{61}}$ M. Lucas Álvarez, P. Lucas Domínguez, El priorato benedictino..., doc. 7, pág. 61.

${ }^{62}$ Ibid., doc. 50, pág. 103.

${ }^{63}$ Dolores MARIÑo Veiras, Señorio de Santa María de Meira (De 1150 a 1525). Espacio rural, régimen de propiedad y régimen de explotación en la Galicia medieval, La Coruña, Ediciones Nos, 1983, págs. 111-112 y 141 (nota 106).

${ }^{64}$ Andrés José Precedo Ledo, Galicia, estructura del territorio y organización comarcal, Santiago de Compostela, Xunta de Galicia, 1987, pág. 70. Alberto José Pazo Labrador, "Notas para el estudio de los asentamientos rurales en Galicia" en Actas do Simposio Internacional Otero Pedrayo e a Xeografia de Galicia, A Coruña, 1989, págs. 149-180. Xosé María Souto GonzÁlez, As parroquias, Vigo, Xerais, 1995, pág. 4. J. FariÑa Tojo, Los asentamientos..., pág. 35. Alberto José PAzo LABRAdor, "La parroquia rural en Galicia: de espacio vivido a contenedor de habitantes" en Susana Reboreda Morillo (coord.), Homenaxe á profesora Lola F. Ferro: estudios de historia, arte e xeografía, Ourense, Universidade de Vigo, 2005, págs. 377-400.

65 J. Fariña Tojo, Los asentamientos..., págs. 53-57 y 111-123.

Abel Bounier, Galicia. Ensaio xeográfico de análisis e interpretación de un vello complexo agrario, Santiago de Compostela, Xunta de Galicia, 2001, vol. 1.

${ }^{66}$ A.J. Pazo Labrador, "Notas para el...”, págs. 160-168. J. Farĩ̃a Tojo, Los asentamientos..., págs. 25-38. X. M. Souto GonzÁlez, “Encol do...”, pág. 29-34.
} 
a la vez que complementarios, procede de la inherente complejidad derivada de la desigual articulación y disposición de un hábitat gallego de tal densidad que cuenta con el mismo número de núcleos de población que el resto de España ${ }^{67}$. Sin embargo, para comprender mejor este paisaje antrópico actual, provisto de tejidos en ocasiones indefinibles, se hará necesario profundizar en el estudio de unos antecedentes evolutivos de raigambre medieval.

Polisemia y ambigüedad terminológica quizás sean los modismos que mejor se adapten a cualquier discurso relacionado con el poblamiento campesino de época medieval; criterio este último, sustentado por las transformaciones y continuismos que la villa significó para la evolución del hábitat en la Edad Media. Si bien es cierto que un análisis en profundidad de estos cambios, debido a condicionantes heurísticos, excede en parte el marco espacial de este estudio, no lo es menos que una breve introducción historiográfica de los mismos ayudaría a comprender la distribución de la población en el periodo y espacio que nos ocupa.

Ya en los años setenta de la pasada centuria los profesores Pallares Méndez y Portela Silva argumentaron que "villa" es uno de los términos susceptibles de ser hallados de forma más recurrente en la documentación gallega altomedieval ${ }^{68}$. En su estudio sobre las explotaciones agrarias durante los siglos IX a XII, de entre ochocientos sesenta y dos documentos consultados llegaron a registrar la presencia de ochocientas noventa y una menciones de la palabra "villa". Tal profusión es el resultado de una ya vieja conocida dualidad semántica derivada de esta locución, que tanto podía designar un núcleo poblacional como una explotación agraria unitaria $^{69}$. Una ambivalencia que no es patrimonio exclusivo de tierras gallegas sino común a todo el norte peninsular, como se puede deducir del examen que llevó a cabo García de Cortázar acerca de la organización social del territorio comprendido entre el Cantábrico y el Ebro: mientras en Asturias de Santillana, Trasmiera y Campóo, zonas donde tuvo mayor incidencia la presencia de Roma, el vocablo "villa" describió en el siglo IX la gran explotación rural, en la zona de Liébana, por el contrario, poco o nada romanizada, ya en los siglos VIII y IX

\footnotetext{
${ }^{67}$ José Carlos SÁnchez PARdo, "Bases para el análisis geohistórico del poblamiento rural tradicional en Galicia”, Boletín de la Asociación de Geógrafos Españoles, 62 (2003), págs. 75-99 y 76.

${ }_{68}$ María Carmen Pallares Méndez, Ermelindo Portela Silva, "Aproximación al estudio de las explotaciones agrarias en Galicia en los siglos IX-XII" en Actas de las primeras jornadas de metodología aplicada a las ciencias históricas. Historia medieval (1973), Santiago de Compostela, Universidad de Santiago de Compostela, 1975, págs. 93-113 y 95.

${ }_{69}$ Una de las conclusiones del estudio arriba citado es la que afirma que para fechas anteriores a 875 se registran un $75 \%$ de referencias documentales vinculadas al concepto de villa-unidad de explotación frente a solamente un $25 \%$ relacionadas con el término villa-unidad de hábitat, porcentajes estos que aproximadamente se mantendrán durante los siglos IX y X.
} 
dicho término fue siempre sinónimo de núcleo poblacional ${ }^{70}$. Sin embargo, en Galicia ambas realidades compartieron, en cierto modo, no sólo la misma cronología (siglos IX y X), sino también idéntico espacio geográfico, como se colige de un documento de 871 extraído de la colección diplomática de Celanova, que evidencia la mencionada coexistencia:

\begin{abstract}
In Dei nomine. Fulgaredus abbas, Petrus presbyter et Berildi Deo vota, domnis invictissimus ac triunfa toribus Sancte Marie Virginis et genitricis Domini nostri Ihesu Christi, et Sancti Georgii et comitum eius, et Sancti Michaelis arcangeli, quorum baselica in territorio in villa ubi dicitur Nantone ubi est ipsa baselica fundata quod dicitur Monasterio, iuxta fluvio Tamare (... $)^{71}$.
\end{abstract}

Este fragmento hace referencia a una basílica advocada a Santa María, que se localiza en la villa de Nantón ${ }^{72}$, presumiblemente reminiscencia de una explotación latifundista que adoptó el nombre del río que junto al Tambre baña parte del territorio de Présaras (A Coruña). En el siguiente fragmento esta basílica es a su vez dotada de diversas villas, junto con otros bienes:

\begin{abstract}
(...) concedimus, ut diximus, villas quas abemus inter Minio et Latera, villa ab integrum cum omni suo accessu (...) sive et alias terras cot conparamus in villas per loca nominatas, sive et alias terras et pomares quod comparamus de Sindina et Sunillone in Roboreto, et alia villa quam abemus iuxta fluvio Tamare (... $)^{73}$.
\end{abstract}

Según se desprende de cuatro documentos de fecha posterior, originarios de Sobrado de los Monjes ${ }^{74}$, la evolución del topónimo Monasterio, que en 871 únicamente estuvo vinculado a la basílica ${ }^{75}$, en 955 pasó a designar una villa y a partir de 966 villa e iglesia desaparecieron para dejar entrar en escena al

\footnotetext{
70 José Ángel García de CorTÁzAr, La formación de la sociedad hispano-cristiana del Cantábrico al Ebro en los siglos VIII al XI. Planteamiento de una hipótesis y análisis del caso de Liébana, Asturias de Santillana, y Trasmiera. Santander, Ediciones de Librería Estudio, 1982, págs. 115-117.

${ }^{71}$ Emilio SÁez y Carlos SÁez, Colección diplomática del ..., vol. 1, doc. 3, pág. 62.

72 Villa recogida por el padre Flórez en su España Sagrada. Henrique Flórez, España Sagrada. Theatro geographico-historico de la iglesia de España, Madrid, Oficina de Pedro Marín, 1789, vol. 17, pág. 25.

${ }^{73}$ E. SÁez y C. Sáez, Colección diplomática del..., doc. 3, pág. 62.

74 M.C. Pallares Méndez, El monasterio de..., doc. 7, pág. 263; doc. 8, pág. 265; doc. 9, pág. 268.

${ }^{75}$ Seguramente recibió el nombre de Monasterio en honor a un antiguo monasterio familiar existente en la misma zona con anterioridad al siglo VIII.
} 
monasterio Santa María de Mezonzo, que con posterioridad daría nombre a una parroquia del actual municipio de Vilasantar. En todo este proceso se aprecia la polisemia que el término "villa" conlleva. Como arriba se apuntó, dicha locución aparece por primera vez en 871, relacionada con un territorio antiguo en el cual se funda la basílica, embrión del futuro monasterio dúplice de Mezonzo, a la que se le conceden igualmente varias villas y tierras. Estas villas, tal como se deduce de dicha donación se otorgan bajo dos modalidades: bien como un todo (villa ab integrum), siendo imposible determinar, por consiguiente, si lo que se cede son explotaciones agrarias completas, o en su defecto, la plena jurisdicción de aldeas; bien como partes de ese todo (et alias terras cot conparamus in villas), discerniéndose gracias a este último supuesto la equiparación de estas villas con aldeas o lugares (per loca nominatas) formadas tanto por terrenos de explotación como por un número indeterminado de núcleos menores de población ${ }^{76}$. Ochenta y cuatro años más tarde, y gracias a la cesión de todas esas villas o parte de las mismas, especialmente las ubicadas iuxta fluvio Tamare (junto al rio Tambre), el término Monasterio ya no permanece por más tiempo adherido a la antigua basílica en cuestión, sino que da nombre a una villa que parece extenderse en torno al mencionado recinto religioso consagrado a Santa María, ocupando una extensión definida entre el Nantón y el Tambre ${ }^{77}$. Aquí es perceptible una última variante de lo que en el siglo X se entendería por villa en diferentes áreas de Galicia: un espacio delimitado y comunicado, coincidente con futuras demarcaciones parroquiales ${ }^{78}$, y caracterizado por una proyección del hábitat a partir de un núcleo originario en el que primitivamente se asentó la iglesia ${ }^{79}$. Una feligresía que nació de la evolución villa-territorio-parroquia que hoy en día recibe el nombre de Mezonzo en honor al antiguo monasterio y actual iglesia parroquial, cuyas advocaciones siempre permanecieron fieles a Santa María.

Un claro ejemplo dentro de la Ribeira Sacra del proceso de sincretismo histórico acaecido a partir del siglo X entre la antigua villa heredera del fundus romano y la parroquia medieval se puede observar en el siguiente extracto del documento que abre la colección diplomática de Pombeiro:

\footnotetext{
76 M. Lucas Álvarez, P. Lucas Domínguez, El monasterio de..., págs. 81 y 88.

77 ...suo uillam que uocitant Monasterio cum ecclesia uocabulo Sancte Marie, que est in loco predicto iuxta duos riuos uocitados Tamare et Nantoni, territorio quidem Presares..., P. LoscerTALES DE GARCía DE Valdeavellano, Tumbos del..., doc. 311, págs. 134-136.

78 María del Carmen Pallares Méndez, Ermelindo Portela Silva, "La villa, por dentro. Testimonios galaicos de los siglos X y XI”, Studia historica. Historia medieval, 16 (1998), págs. 18-24.

79 José Carlos SÁnchez PARdo, Territorio y poblamiento en Galicia entre la antigüedad y la plena Edad Media, Universidade de Santiago de Compostela, Santiago de Compostela, 2008, pág. 554.
} 
(...) Villam quan inquiunt Kaneta, quod est sub terminis ecclesie Sancte Eulalie pro suis terminis antiquis, qui sunt: Contra parte orienti pro termino de Sendalizes; contra parte septentrioni per terminus de Basconis; contra occidenti pro terminis de Sancto Vincentio de Pino et pro terminus de Petrauzos; contra parte meridie pro termino de Nozeta(...). Damus vobis casas, profectus atque palatia, cupos, cupas, lectos, caligeiras, et omnia outensilia intus domum, forinsecus autem exitum et regresum, montes et ligna, pratis, pascuis, pallullibus, terras cultas vel invarvaras, petras mobiles et inmobiles, fontes et valles $(. . .)^{80}$.

Aquí la villa ya se encuentra dentro de los términos de la iglesia de Santa Eulalia, que pasaría a ser su sede parroquial. El interés de este texto reside en la claridad con la que se muestra el proceso de sustitución de la villa por la parroquia, entendidas ambas como territorios que no sólo acogieron diversos modelos de hábitat, sino que también cumplieron su propósito de fijar y encuadrar a la población con fines administrativos y fiscales. De este modo, la antigua villa de Kaneta daría paso a la parroquia de Santa Eulalia de Caneda, perteneciente al actual municipio de Monforte de Lemos. No obstante, esta fase continuista dista mucho de ser aplicable en todas las ocasiones y lugares. Así lo revela el mismo documento dotacional por el que igualmente se otorgó la villa de Fradelo en Castillón (municipio de Pantón) al monasterio de Pombeiro; a diferencia del supuesto anterior, ni parroquia ni siquiera entidad poblacional alguna han llegado a conservar como propio este topónimo, que se ha desvanecido en el transcurrir de los siglos. Un claro ejemplo de que la villa-núcleo poblacional como arquetipo del hábitat gallego de este periodo convivió con la villa "clásica" durante su fase de conversión en feligresía se halla en el siguiente diploma del tumbo de Celanova, que reproduce la venta realizada por Placia de la quinta parte de los bienes recibidos de su marido en la villa de Quiroga:

In Dei nomine. Ego Placia vobis Vimara presbiter. Placuit michi atque convenit ut facerem vobis scriptura venditionis, sicut et facio, de quinta abeo de marido nomen Illallo in ipsa sua villa ubi dicent Carioga $(\ldots)^{81}$.

Localidad la de Quiroga emplazada en el extremo oriental de la Ribeira Sacra, que ha perdurado hasta nuestros días como claro ejemplo de hábitat concentrado.

\footnotetext{
${ }_{80}^{80}$ M. Lucas Álvarez, P. Lucas Domínguez, El priorato benedictino..., doc. 1, pág. 53.

${ }^{81}$ E. SÁEz y C. SÁEz, Colección diplomática del..., doc. 37, pág. 104.
} 
Un modelo de poblamiento que fue característico de las villas de corte "antiguo" antes de la estructura dispersa protagonizada por la expansión agraria que ya se puede atisbar a finales del siglo $\mathrm{X}^{82}$. Es por todo lo expuesto por lo que a partir del siglo XI la polisemia relativa al término villa llegó a su fin al verse sustituida en su acepción clásica por la parroquia, quedando su variante poblacional equiparada a la aldea ${ }^{83}$. Paradójicamente, es a partir de esta centuria cuando la villa-aldea empezaría a perder protagonismo como bien sujeto a negocio jurídico, en favor de entidades de población menores que, dentro de un modelo de hábitat disperso dominante en los siglos posteriores, se diseminaron por el medio rural gallego ${ }^{84}$. De este modo, la aldea del siglo XIII se pudo ordenar según dos categorías, dada su disposición inicial, significándose en ambas el casal como su elemento fundamental: por un lado el casal aislado y superpoblado por varias familias, que con el tiempo se configuró en aldea; por el otro el casal yuxtapuesto a otros similares, estructurando de este modo una aldea ${ }^{85}$. Ambas variantes constituyeron la población del actual municipio de Pantón en la baja Edad Media, siempre en el seno del marco espacial que definió a la parroquia en su función de agente articulador del territorio y sus habitantes. El término aldea, en cambio, inexistente en los diplomas relativos a tierras pantonesas hasta bien entrado el siglo $\mathrm{XV}$, se registra a partir de entonces sólo en dos ocasiones, circunstancia lógica teniendo en consideración que en este periodo lo que se enajena son las unidades de explotación y habitación, es decir las partes que conforman la aldea, y en ningún caso la jurisdicción de la totalidad de las mismas, tal como sucedía en periodos precedentes. De modo que estas entidades de población únicamente se documentan ante la necesidad de esclarecer la ubicación geográfica de propiedades, sean estas una serie de bienes dentro de la aldea de Pesqueiras o una viña en las proximidades de la de Maside ${ }^{86}$.

Los testimonios en los que el casal se revela como elemento formador de núcleos de hábitat mayores no son muy abundantes, debido en gran parte al exclusivo interés económico de una documentación foral dirigida a tratar estos enclaves como simples unidades de producción generadoras de renta y de determinadas obligaciones señoriales. Quizás el de Budián, en la parroquia de San Román de

\footnotetext{
${ }_{82}$ María del Carmen Pallares Méndez, "El poblamiento rural gallego en la Edad Media”, Obradoiro: revista de arquitectura y urbanismo, 2 (1978), págs. 3-14.

${ }^{83}$ Ermelindo Portela Silva, La Región del obispado de Tuy en los siglos XII a XV. Una sociedad en la expansión y en la crisis, Santiago de Compostela, El Eco Franciscano, 1976, págs. 77-78.

84 J. C. Sánchez Pardo, Territorio y..., págs. 532-533.

${ }^{85}$ María Carmen Pallares Méndez, Ermelindo Portela Silva, "De la villa del siglo IX a la aldea del siglo XIII: Espacio agrario y feudalización en Galicia”, Asturiensia medievalia, 8 (1995-1996), págs. 60-61 y 64.

${ }^{86}$ En 1428, M. Lucas Álvarez, P. Lucas Domínguez, El priorato benedictino..., doc. 119, pág. 192, aldea de Pesqueiras y en 1468, J.I. Fernández de Viana y Vieites, Colección diplomática del..., doc. 193, pág. 242, aldea de Maside.
} 


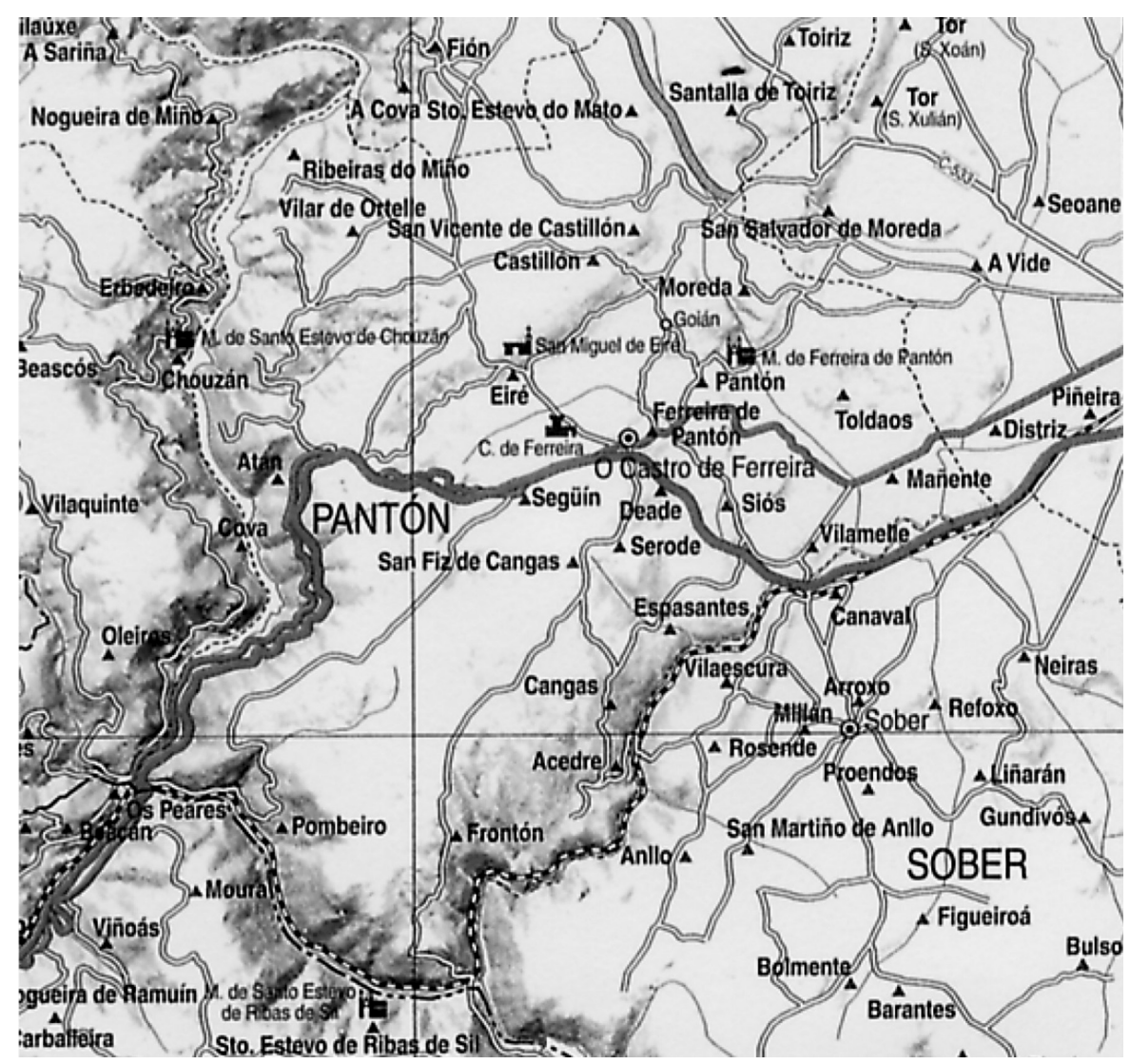

Fig. 6. Mapa de Pantón. Fuente: Cartografía Digital [en línea], disponible en https://digimapas.blogspot.com.es [Consulta: 19/04/2012].

Acedre, sea el caso más significativo de una aldea formada por la agrupación de diversas entidades menores debido a la integración en su seno tanto del casal de Fondo de Vila como del lugar de Piñeiro ${ }^{87}$.

Existen otros ejemplos en los que la tendencia a la formación de aldeas polinucleares dentro de un hábitat predominantemente disperso se hace más y más evidente, especialmente durante el siglo XV. Así, el lugar de San Adrián, en la feligresía de Santa María de Ferreira, se presenta como una concentración de diversos casales, cuyos moradores quedan exentos del pago de moneda forera al demostrarse que seguían siendo vasallos del monasterio de Ferreira ${ }^{88}$.

\footnotetext{
87 J.I. Fernández de Viana y Vieites, Colección diplomática del..., doc. 129, pág. 156; doc. 204, pág. 258.

${ }^{88}$ Ibid., doc. 108, pág. 129.
} 
En semejantes términos, A Costa y Outeiro, ambas entidades sitas en la parroquia de Pantón, aparecen mencionadas en relación con el aforamiento de cuatro lugares diferentes ubicados todos ellos dentro de dichas localidades y explotados por al menos igual número de grupos familiares ${ }^{89}$.

Finalmente, puede que sea pertinente referirse al casal de Cabo de Vila, situado en la feligresía de Vilamelle, el cual nada menos que en tres ocasiones en un periodo de dieciséis años consta como bien aforado ${ }^{90}$, por lo que es más que presumible que Cabo de Vila no se refiriese al nombre del casal en cuestión sino a un núcleo de mayor entidad en el que estas tres unidades de población fueron objeto de contrato foral.

Según se desprende de la colección diplomática del monasterio de San Salvador de Asma, la presencia de casales, formando parte del entramado aldeano, se encuentra también documentada en la limítrofe comarca de Chantada. De este modo, diferentes abades del mencionado monasterio aforaron en un intervalo de cuarenta años (1383-1423) dos casales distintos localizados en la misma aldea de Casteda, parroquia de $\operatorname{Arcos}^{91}$. Sin embargo, quizás la imagen más nítida que se pueda llegar a tener de la fisonomía una aldea de primera mitad del siglo XIV (1338) se halle en el acta levantada por el notario público de Chantada de las heredades y casas pertenecientes al monasterio en la aldea de Sitiós (parroquia de Santa Uxía de Asma), según la cual, esta localidad estaría constituida por un casal (formado a su vez por siete casas), otras siete casas que ocuparían otros dos grupos familiares y un número indeterminado de casales pertenecientes tanto al monasterio de Oseira como a un individuo conocido por Derraman ${ }^{92}$.

Ha sido comúnmente aceptado por historiadores y geógrafos el continuismo que las redes de hábitat aldeano protagonizaron en cuanto a estructura y distribución, desde la época plenomedieval hasta la actualidad ${ }^{93}$. En lo que se refiere a las tierras de Pantón, esta premisa también parece cumplirse. Hoy día, en la distribución de la población propia de estas tierras predominan los dos modelos generalizados por Fariña Tojo para el interior agrícola gallego ${ }^{94}$ : el polinuclear con caserío claro y el nuclear en nebulosa, siendo la diferencia entre los dos mínima, ya que ambos tipos presentan una formación de casales o núcleos menores de

\footnotetext{
${ }_{89}$ M. Lucas Álvarez, P. Lucas Domínguez, El priorato benedictino..., doc. 202, pág. 276.

90 J.I. Fernández de Viana y Vieites, Colección diplomática del..., docs. 65, 66, 76, págs. 83-84 y 96.

91 J. Méndez Pérez; P.S. Otero Piñeyro Maseda; M. Romaní Martínez, El monasterio de San Salvador..., doc. 127, págs. 396 y 397; doc. 161, págs. 447-449.

92 Ibíd., doc. 71, págs. 296-301.

93 José Carlos SÁnchez PARdo, "Una propuesta de análisis geohistórico de las aldeas tradicionales gallegas”, Cuadernos de Estudios Gallegos, 120 (2007), págs. 103-134 y 105.

94 J. FARIÑa Tojo, Los asentamientos..., págs. 115-116.
} 


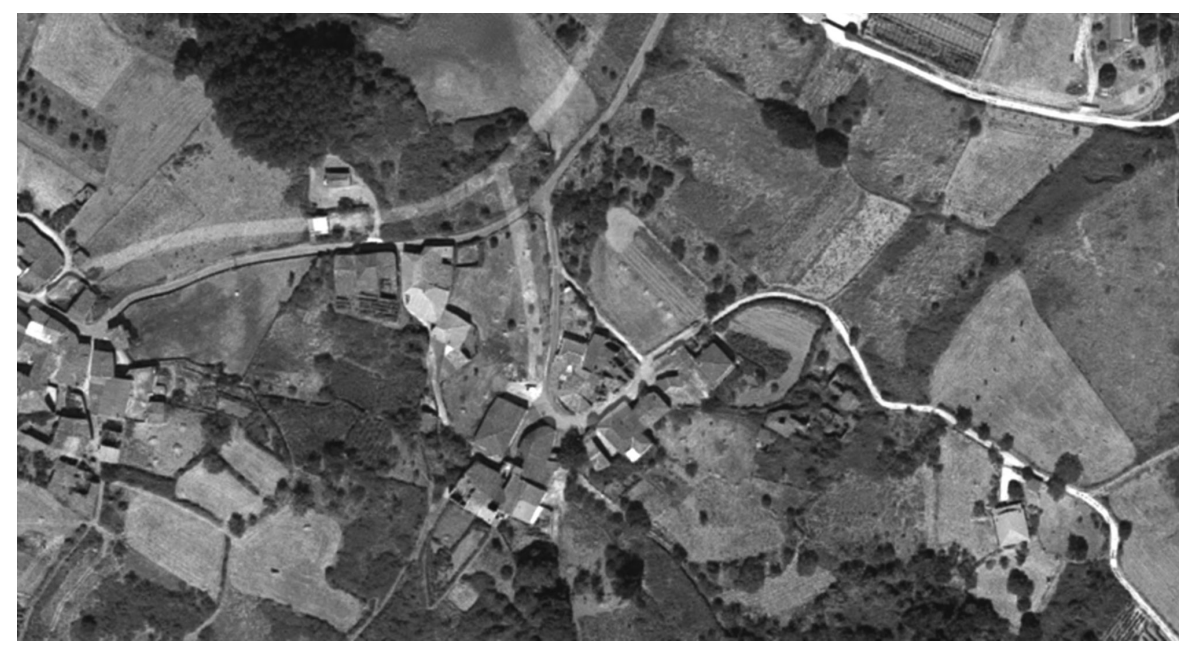

Fig. 7. Panorámica aérea de Budián.

Fuente: elaboración propia a partir de Google Maps.

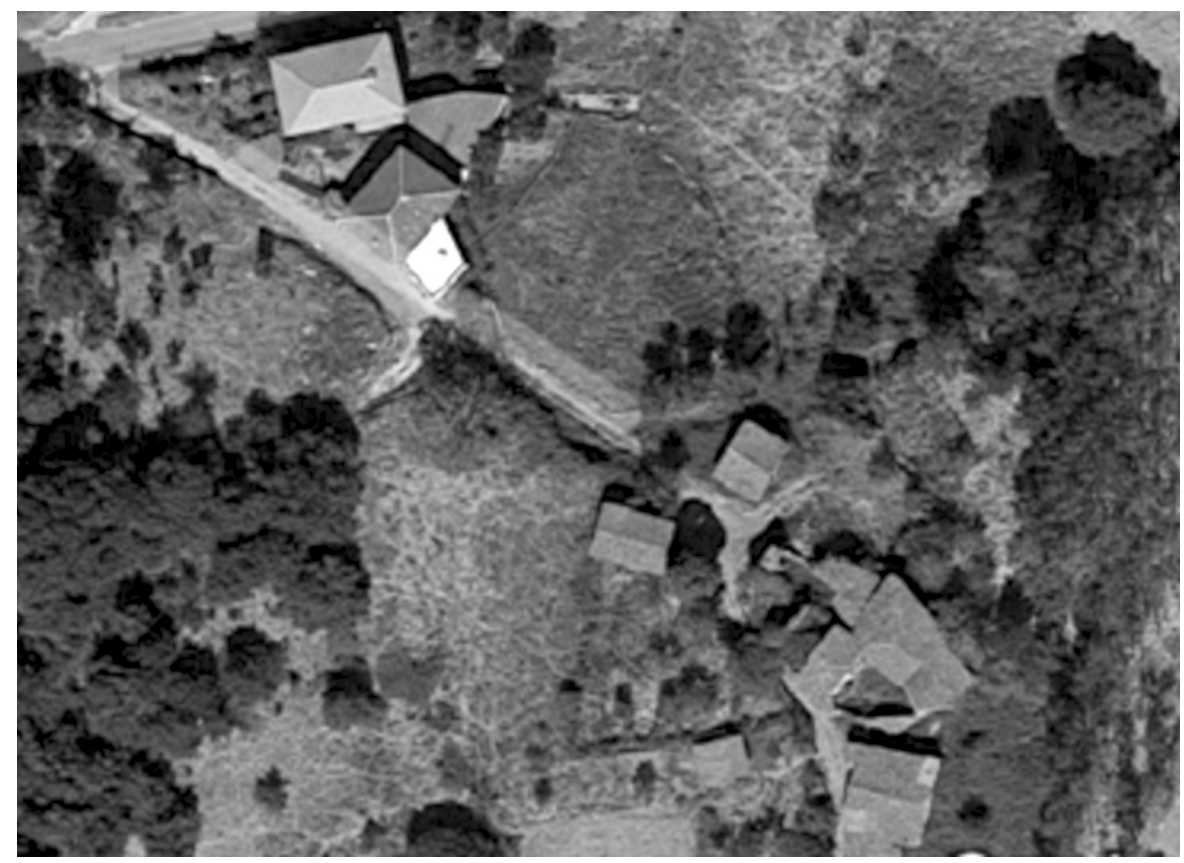

Fig. 8. Panorámica aérea de San Adriao.

Fuente: elaboración propia a partir de Google Maps. 
población. En el polinuclear las separaciones físicas entre las casas no llegan a eliminar la diferencia entre los distintos núcleos, mientras que en el nuclear en nebulosa las formaciones de casales presentan una menor entidad, a la vez se hace difícil precisar la primacía de unas unidades sobre las otras. En consecuencia, se puede llegar a argumentar que en la actualidad el espacio que ocupa este estudio se caracteriza por un hábitat mayoritariamente disperso en multitud de pequeñas entidades de población ${ }^{95}$. Afirmación esta que parece armonizar con conclusiones de análisis geohistóricos relativos a otras áreas de Galicia que asocian las estructuras dispersas con morfologías suaves y suelos fértiles ${ }^{96}$, evidenciando el dominio de la concentración del hábitat en áreas mucho más montañosas ${ }^{97}$. Este es el caso de la Tierra de Lemos, donde la referida dispersión se encuentra en el grado de "pequeños agrupamientos", de seis a diez casas y de cincuenta habitantes como máximo ${ }^{98}$. En lo relativo al actual municipio de Pantón, estos núcleos de reducidas dimensiones alcanzan en el presente el número de 273 , de entre los cuales 126 , un $46 \%$, ya están documentados en las colecciones diplomáticas de los monasterios de Ferreira, Pombeiro y Monforte, así como en el tumbo de la catedral de Lugo. La ausencia testimonial del resto de entidades integradoras de un hábitat aldeano ya plenamente constituido en la baja Edad Media se debe, en primer lugar, a su absentismo documental como objeto de transacción señorial, y en segundo lugar, a la más que frecuente desaparición y diseminación de diplomas, a causa tanto de los procesos desamortizadores como de las constantes apropiaciones indebidas ejercidas por particulares. Llegados a este punto es importante señalar que durante el examen de estos mismos fondos se han constatado otros 87 entes de población que no sobrevivieron a la inexorabilidad del paso del tiempo ${ }^{99}$. Aplicando el mismo porcentaje del $46 \%$ en relación con la totalidad, válido para los enclaves ya identificados, se podría defender la existencia entre los siglos XIV y XV para el actual municipio de Pantón de al menos 189 entidades de población hoy desaparecidas, pero que habrían formado parte de una red de al menos 462 núcleos de población distribuidos a lo largo y ancho de 26 parroquias. De este modo, una conclusión se antoja como evidente: la que exhibe para el periodo estudiado un hábitat mucho más disperso que el actual, pero también con bastante más densidad de población, seguramente como resultado no solo

\footnotetext{
95 Ibid., págs. 43 y 55-56.

96 Por otro lado rasgos definitorios de las tierras de Pantón en particular y del valle de Lemos en general.

97 J. C. SÁnchez PARdo, "Una propuesta...”, pág. 122.

98 Pedro de Llano Cabado, Arquitectura popular en Galicia: razón e construcción, Santiago de Compostela, Colexio Oficial de Arquitectos de Galicia, Comisión de Cultura, 1989, vol. 1, pág. 25.

${ }_{99}$ Seguramente porque fueron lugares o casales unifamiliares aislados y sin ningún nexo físico con entidades de población mayores que sobrevivieron como estructuras aldeanas.
} 


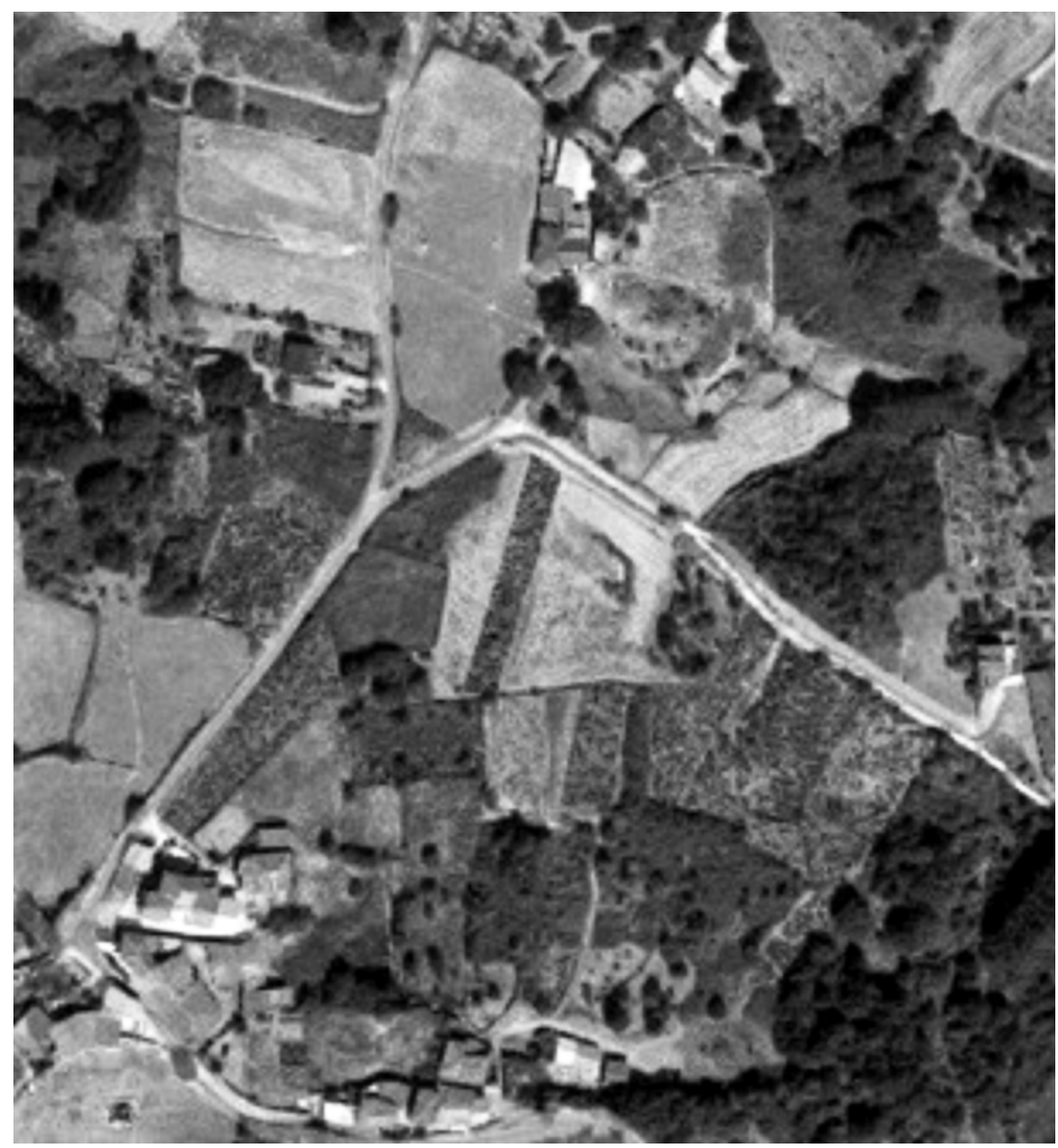

Fig. 9. Panorámica aérea de A Costa y Outeiro.

Fuente: elaboración propia a partir de Google Maps.

de una intrínseca necesidad del campesinado relativa a no identificar dispersión con aislamiento, sino también de una continuada política de fraccionamiento del patrimonio hereditario, incluso el aforado, claramente observable en áreas de la Ribeira Sacra desde principios del siglo XIV ${ }^{100}$.

\footnotetext{
${ }^{100}$ Isabel Alfonso AnTón, "La Comunidad campesina" en Reyna Pastor de Togneri (coord.), Poder monástico y grupos domésticos en la Galicia foral (siglos XIII-XV). La casa. La comunidad, Madrid, CSIC, 1990, págs. 354-355.
} 


\section{EL LUGAR, EL CASAL Y LA CASA}

Ambiguo y polisémico no son calificativos que posea en exclusiva el binomio villa-parroquia vs. villa-aldea; más bien proyectan una sensación de tenacidad incesante desde la documentación de la época. De hecho, y dependiendo de la diversidad de fuentes estudiadas, o incluso siendo estas las mismas, la confusión terminológica por la que lo nominal puede o no corresponder con lo conceptual suele derivar en variadas interpretaciones que atañen a la esencia misma de las unidades básicas del poblamiento rural gallego. Un claro ejemplo de tal anfibología se encuentra en el ya de por sí impreciso vocablo "lugar", que para Fariña Tojo constituye una entidad básica que puede asociarse o no a una aldea, o en su defecto ser parte de la misma ${ }^{101}$. Desde un punto de vista algo más profano, pero quizá más perceptivo, Castelao lo definió como "As casas espalladas, forman un grupo natural de poucos habitantes, chamado lugar"102. Desde una perspectiva más sociológica se le podría considerar como una comunidad mínima de base social, de sentido ecológico y de orden económico ${ }^{103}$. La controversia ya dentro del ámbito historiográfico-geográfico nace de la ambivalencia de significado que del término se infiere en los testimonios escritos, especialmente en el transcurso del Medioevo. No es de extrañar que, dependiendo de la fuente en cuestión, se interprete el lugar como la célula habitacional primaria sobre la que se erigirá la futura aldea ${ }^{104}$, o como una entidad homóloga a la aldea en sí misma ${ }^{105}$, o, incluso, como sinónimo de parroquia ${ }^{106} \mathrm{o}$, más razonablemente, de casal ${ }^{107}$.

No hay duda de que la documentación concerniente a las tierras de Pantón se alinea con la predisposición hacia la incertidumbre semántica tan común en toda Galicia. De este modo, la actual aldea de Amandi, en la feligresía de Pombeiro y de una treintena de habitantes, aparece mencionada primero como lugar en $1422^{108}$, y un par de años más tarde como aldea ${ }^{109}$. Sin embargo se puede conjeturar, teniendo presente la disposición interna de Amandi hoy día, que en el siglo XV esta población estuvo formada por diversos lugares que recibieron su nombre del topónimo de la entidad mayor en la se encontraban ubicados. Un caso similar es

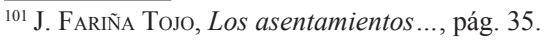

102 "Las casas desparramadas, forman un grupo natural de pocos habitantes, llamado lugar" en Alfonso Daniel Rodríguez Castelao, Sempre en Galiza, Buenos Aires, Edición “As Burgas”, 1961, págs. 117-118. ${ }^{103}$ Baldomero Cores Trasmonte, Sociología Rural de Galicia, A Coruña, Librigal, 1973, pág. 175.

${ }^{104}$ Xosé Farĩ̃a JAmardo, El hábitat gallego, La Coruña, Diputación provincial de La Coruña, 1981, pág. 85.

${ }^{105}$ Georg Niemeier, "Tipos de población rural en Galicia”, Estudios geográficos, vol. 6, 19 (1945), págs. 301-327 y 308 .

${ }^{106}$ Alberto SAmpaio, As "villas" do norte de Portugal: estudo sobre as origens e estabelecimento da propriedade, Oporto, Imprensa Moderna, 1903, pág. 299.

${ }^{107}$ M. Lucas Álvarez, P. Lucas Domínguez, El monasterio de ..., pág. 81.

${ }^{108}$ Íd., El priorato benedictino..., doc. 105, pág. 176. ...lugar d'Amande....

${ }^{109}$ Ibíd., doc. 110, pág. 181. ... aldea d'Amande....
} 
el de Pesqueiras, pequeña localidad en Atán, de unas quince almas, que en 1428 se la conoció como aldea ${ }^{110}$, mientras que en 1482 se la documenta como lugar objeto de contrato foral ${ }^{111}$. No obstante, lo que va más allá de la evidencia, según se desprende de los fondos monacales, es la sinonimia existente durante todo el periodo bajomedieval entre el casal y el lugar, aunque, eso sí, siempre formando ambas realidades parte de un núcleo aglutinador aldeano que ha perdurado hasta el presente. Es el caso de A Ermida (San Vicente de Castillón) ${ }^{112}$, Campelos (San Martiño de Siós) ${ }^{113}$, Outeiro (San Martiño de Siós) ${ }^{114}$ y Outeiro (San Martiño de Pantón $)^{115}$. Este último caso, el de Outeiro de Pantón, es paradigmático de lo expuesto, como lo demuestra el hecho de que se afore... a metad do meu lugar e casal do Outeiro de Pantom... ${ }^{116}$.

Es bien sabido que tanto casal como lugar tuvieron su origen en el proceso de expansión agrícola, que descuidó las viejas estructuras propensas a una nuclearización defensiva altomedieval en favor de un ordenamiento diferente caracterizado por una atomización poblacional y nacido de la iniciativa personal roturadora $^{117}$. No obstante, debido a la posibilidad de enajenar estos enclaves de forma fragmentaria, pronto fue factible la constitución de nuevos casales y lugares que, con el tiempo, originarían un núcleo más concentrado ${ }^{118}$. En este punto me parece oportuno rescatar de las colecciones diplomáticas de San Salvador de Celanova y de Santa Cristina de Ribas de Sil la noción que a fines del siglo XV se tenía tanto de un casal en el primer caso como de un lugar en el segundo, para de este modo consolidar la hipótesis que defiende la homogeneidad entre ambas singularidades. En 1484 el procurador del monasterio de Celanova solicita que se haga la demarcación de un casal sito en la aldea de Nigueiroá (municipio de Rairiz de Veiga, Ourense); dicho casal comprendía la mitad de una casa, una corte, tres cuadras, un granero, diecisiete terrenos junto con dos leiros y una leira todos ellos de cereal, un prado, una cortiña con castaños, una huerta y un terreno y medio de linar ${ }^{119}$. Dos años antes, y a unos ochenta y cinco kilómetros de distancia, el administrador de Santa Cristina aforó a un matrimonio un lugar emplazado

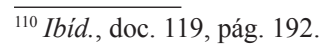

${ }^{111}$ Ibid., doc. 254, pág. 320.

${ }^{112}$ Ibíd., doc. 44, pág. 96; J.I. FernándeZ De Viana y Vieites, Colección diplomática del..., doc. 49, pág. 64.

${ }^{113}$ J.I. Fernández de Viana y Vieites, Colección diplomática del..., doc. 82, pág. 103; ibíd., doc. 116, pág. 138.

${ }^{114}$ Ibíd., doc. 30, pág. 44; Ibíd., doc. 126, pág. 152.

${ }^{115}$ M. Lucas Álvarez, P. Lucas Domínguez, El priorato benedictino..., doc. 280, pág. 346.

${ }^{116}$ Ibid.

${ }^{117}$ Ermelindo Portela Silva, "La propiedad, el trabajo y los frutos de la tierra en la Galicia Medieval (9001300)", Liceo Franciscano, 31 (1978), págs. 157-200 y 192.

${ }^{118}$ M. Lucas Álvarez, P. Lucas Domínguez, El monasterio de..., pág. 80.

${ }^{119}$ María Beatriz Vaquero Díaz, Colección diplomática do Mosteiro de San Salvador de Celanova (Ss. XIII-XV), Santiago de Compostela, Tórculo, 2004, vol. 3, doc. 757, págs. 37-39.
} 
en la aldea de Rosende (Sober, Lugo) y formado por dos casas con su bodega y cortiñeiro; cinco terrenos más, cuatro leiras y un leiro, dedicados todos al cereal, trece cavaduras de viña, una cortiña, un leiro con manzanos y treinta castaños ${ }^{120}$. Parece evidente, al margen de la similitud en cuanto a estructura, la transcendencia conferida a la explotación agropecuaria de la que casales y lugares participaron.

El casal galaico-portugués se consolidó como el equivalente a la casería asturiana o el solar castellano, es decir un conglomerado de propiedades que componen una explotación familiar, concentradas en torno a la vivienda y sus dependencias o en otras partes del terrazgo que completa la unidad básica ${ }^{121}$. Estos establecimientos, en consecuencia, sobresalieron como centros por excelencia de emisión de renta señorial, y entre sus elementos estructurales destacaron una casa de habitación y sus anexos, también llamados casas, así como una o varias huertas o cortiñas, tierras de labradío y terrenos incultos ${ }^{122}$. Tal configuración estaba encaminada a alcanzar una productividad tanto agrícola como ganadera, resultado del requerimiento fiscal asignado a estos entes socioeconómicos ${ }^{123}$. A pesar de la nula información sobre superficies de las fuentes del periodo, Bouhier, en el área de dominio de San Pedro de Rocas, fijó la extensión de estas células de habitación y explotación dentro de un abanico que iría de 1,20 a 6 hectáreas, estimando una superficie media para cada casal de entre dos y tres hectáreas ${ }^{124}$.

En lo que respecta a la vivienda campesina, la política monástica se centró en exigir su buen estado de conservación y, si fuese menester, incluso su plena edificación ${ }^{125}$, así como también en imponer los materiales de estas construcciones, seguramente con el fin de asegurar cierta solidez y perdurabilidad. De esta forma, la teja, la paja o el colmo y la madera estuvieron presentes en los tejados ${ }^{126}$. La cubierta de la casa, sin lugar a dudas, ocupó un lugar de primer orden en las

\footnotetext{
${ }^{120}$ AHPO, sección clero, libro 664, fols. 252v-254r.

${ }^{121}$ André Evangelista MARQues, O casal: uma unidade de organização social do espaço no Entre-Douro-e-Lima (906-1200), Noia (A Coruña), Toxosoutos, 2008, págs. 120-123.

${ }^{122}$ A. Bouhier, Galicia. Ensaio..., vol. 2, pág. 1212.

${ }^{123}$ María Luz Ríos Rodríguez, "El casal medieval gallego: contribución al estudio de una unidad de poblamiento y explotación (siglos XI al XIII)”, El Museo de Pontevedra, 43 (1989), págs. 116-118.

${ }^{124}$ A. Bouhier, Galicia. Ensaio..., vol. 2, pág. 1289.

${ }^{125}$ M. Lucas Álvarez, P. Lucas Domínguez, El priorato benedictino..., doc. 239... et corregades as casas et as tenades bem paradas...., pág. 307. Ibíd., doc. 153... Outrosy vos aforamos herdade en que façades duas casas..., pág. 229.

${ }^{126}$ Ibid., doc. 133... con huna casa tellada que hy esta, que he deste herdamento...., pág. 206; J.I. FERNÁNDEZ de ViAna y Vieites, Colección diplomática del..., doc. 207...e cubriredes a meetade da cassa da parte da nosa orta de tella...., pág. 263. J.I. FernándeZ de VianA y Vieites, Colección diplomática del..., doc. 180...e teñades as cassas feitas e cubiertas de madera e de palla...., pág. 224. E. Duro PeñA, El monasterio de..., doc. 78 , pág. 188: una de las condiciones principales del foro fue la de la edificación a cargo del forero de unas casas en el seno de un casal en los dous annos primeiros que veen, e as cubrades de madeira e de colmo.
} 
preocupaciones del campesino a la hora de levantar su morada. Circunstancia que no es de extrañar si se tiene presente la dificultad que entrañaba no solo su instalación, sino también su conservación frente a las inclemencias meteorológicas ${ }^{127}$. Desvelo que los rectores monásticos compartieron, a su manera, exigiendo el mantenimiento de las viviendas cubiertas y en perfectas condiciones por medio de las cláusulas forales ${ }^{128}$. El campesinado utilizó para la elaboración de sus cubiertas los materiales que eran más asequibles, siempre de acuerdo con la exigencia del clima y del territorio ${ }^{129}$. Uno de los más difundidos en la baja Edad Media, y en la actualidad de presencia marginal en escasas y localizadas áreas, fue el colmo o paja de centeno. Su fácil adquisición, su liviandad y su capacidad para cubrir bien y guardar con eficacia el calor interior de las viviendas constituyeron las razones claves que explicaron su éxito ${ }^{130}$. No obstante, fue la techumbre de teja la que ha prevalecido en la Ribeira Sacra rural hasta nuestros días. Este tipo de cobertura, introducida por los romanos, ha garantizado un revestimiento inmejorable, ya que gracias a su peso y a su forma cóncava, ha ido haciendo frente de manera inmejorable a los efectos tanto de la lluvia como del viento ${ }^{131}$. La madera y la piedra fueron los elementos constructivos más difundidos en cualquier tipo de edificación ${ }^{132}$. Las propiedades de la madera para resguardar al campesino del frío y la resistencia de la piedra al fuego y al agua, así como la disponibilidad de ambos materiales, fueron los condicionantes que justificaron su uso generalizado ${ }^{133}$.

En cuanto a la estructura y distribución interna de las viviendas campesinas nada aporta la documentación. Sin embargo, es lógico pensar en las moradas como resultado de unos métodos de edificación bastante simples, teniendo en mente un periodo en el que el habitante de estas tierras, además de labriego, estuvo forzado a ser constructor ${ }^{134}$. No hay que olvidar que el hogar familiar y sus anexos estuvieron estrechamente unidos desde que su erección se supeditó no solamente a los materiales que ofrece el terreno circundante, sino también a los condicionantes técnicos y económicos que exige la explotación agropecuaria. De este modo, todo en los lugares de habitación debía su existencia a su funcionalidad dentro del

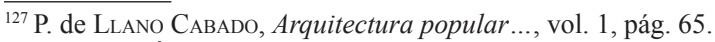

${ }^{128}$ M. Lucas Álvarez, P. Lucas Domínguez, El priorato benedictino..., doc. 102...e con tal condiçon que moredes o dito lugar e tenades as ditas casas cuuertas e ben paradas...., pág. 174.

${ }^{129}$ Ramón Otero Pedrayo, Historia de Galiza, Buenos Aires, Ediciones Nos, 1962, vol. 2, pág. 40.

${ }^{130}$ Xoaquín Lorenzo Fernández, A casa, Vigo, Galaxia, 1982, pág. 41.

${ }^{131}$ P. de Llano Cabado, Arquitectura popular..., vol. 1, pág. 70.

${ }^{132}$ E. Duro PeÑA, El monasterio de..., doc. 218, pág. 248: Entre las condiciones de este foro a cumplir por parte del receptor del mismo se encuentra la de corregir una casa de pedra e de madeyra e de tella e que seja asobrada.

${ }^{133}$ Robert Fossier, Historia del campesinado en el Occidente Medieval, Barcelona, Crítica, 1985, págs. 72-73.

${ }^{134}$ María del Carmen Sánchez CARrera, El Bajo Miño en el siglo XV. El espacio y los hombres, A Coruña, Fundación "Pedro Barrié de la Maza", 1997, pág. 84.
} 
exiguo universo de la productividad, no dejando nada a lo trivial y sacrificándolo todo, incluso el bienestar de sus moradores, en aras de dicho bien mayor ${ }^{135}$. De modo que, aunque fuese posible que las viviendas campesinas alcanzasen los dos $\operatorname{pisos}^{136}$, los problemas de equilibrio que implicaba en la estructura la apertura de ventanas y la falta de cristal para cubrir las mismas, unido al intenso viento gélido del invierno que se colaba por todos los resquicios, hacía de la casa labriega un lugar oscuro, iluminado trémulamente por el fuego del hogar, velas o candiles ${ }^{137} \mathrm{y}$ dotado solamente de pequeños orificios con el objetivo de favorecer una mínima ventilación ${ }^{138}$. La escasa aireación en el interior distaba de ser una opción; ante el temor a helarse por los rigores del frío durante buena parte del año, los campesinos no tuvieron más remedio que "asfixiarse" por el humo de los hogares y los hedores desprendidos de la consabida falta de higiene de esta época ${ }^{139}$.

\section{Conclusiones}

El primer punto que merece la pena abordar en este apartado final es la matización de los rasgos idiosincráticos inherentes al espacio objeto de este estudio. En un lugar destacado se debería colocar la tendencia a la dispersión del hábitat que ha caracterizado a las tierras de Pantón al menos desde principios del siglo XIV. Una atomización que, debido en parte las peculiares características edafológicas de la zona y a un generalizado fraccionamiento de la propiedad, no solo afectó a las entidades de poblamiento, sino también a las pequeñas unidades de explotación. Como consecuencia inmediata la parroquia, ya plenamente configurada en la documentación en el siglo XII, se consolidaría a través de los siglos como el elemento articulador de un universo rural demasiado diseminado, en primera instancia, para poder ser efectivamente controlado por los distintos poderes señoriales. Si la parroquia fue el instrumento típico por el cual se pudo garantizar la estructuración del territorio y el encuadramiento de la población, sin duda fue el coto, como centro primigenio de poder jurisdiccional, el que mejor personificó la identificación del hábitat con el preludio de la expansión patrimonial monástica. Llegados a este punto, parece pertinente recordar el continuismo del que tanto la parroquia como el coto han participado desde su constitución hasta nuestros días: mientras que la parroquia ha permanecido invariable desde la plena Edad Media, el coto por su parte, en muchos casos, aún es plenamente reconocible

\footnotetext{
${ }^{135}$ Philippe Ariès, Georges Duby (dirs.), Historia de la vida privada. De la Europa feudal al Renacimiento, Madrid, Taurus, 2001, vol. 2, pág. 461.

${ }^{136}$ P. de Llano CABAdo, Arquitectura popular..., vol. 1, pág. 49.

${ }^{137}$ Norman J. G. Pounds, La vida cotidiana: Historia de la cultura material, Barcelona, Crítica, 1992 , pág. 253.

${ }^{138}$ M. C. SÁnchez Carrera, El Bajo..., pág. 94.

${ }^{139}$ N. J. G. Pounds, La vida ..., pág. 251.
} 
al coincidir sus antiguos términos con actuales demarcaciones municipales. La red de poblamiento aldeana tampoco fue ajena a tan significante expresión de perdurabilidad como se infiere de la presencia en los foros bajomedievales pantoneses de casi la mitad de todas las entidades de población identificables en la actualidad. Otro aspecto que comparte esta línea continuista es el relativo a la configuración de los núcleos de población. Al no manifestarse nominalmente la aldea en la documentación hasta el siglo XV, el entramado habitacional, según la documentación foral, se fue constituyendo alrededor del casal y del lugar. De este modo, el hábitat a partir del siglo XIII se estructuró por medio de una doble tipología: en la primera, aparece el casal aislado, superpoblado, fraccionado por las herencias y con el tiempo transformado en una pequeña aldea o lugar; en la segunda, predomina el casal yuxtapuesto a otros semejantes configurando entre todos una aldea. Ambos modelos cumplirán con el tiempo un papel transcendente en la configuración de una red de entidades de población diseminadas por el territorio cuya principal peculiaridad es una disposición polinuclear, nítida reminiscencia perceptible incluso en nuestros días de la formación de la aldea mediante la agrupación de diversos casales.

\section{BIBLIOGRAFÍA}

Amaral, Luis Carlos, Formação e desenvolvimento do domínio da diocese de Braga no período da Reconquista (século IX-1137), tesis doctoral, Oporto, Universidad de Oporto, 2007.

Andrade Cernadas, José Miguel, El monacato benedictino y la sociedad de la Galicia medieval (siglos X al XIII), Sada (A Coruña), Edicios do Castro, 1997.

Ariès, Philippe, Duby, Georges (dirs.), Historia de la vida privada. De la Europa feudal al Renacimiento, Madrid, Taurus, 2001.

Arízaga Bolumburu, Beatriz et alii, Mundos medievales. Espacios, sociedades y poder: homenaje al profesor José Ángel García de Cortázar y Ruiz de Aguirre, Santander, Universidad de Cantabria, 2012.

Aubrun, Michel, La paroise en France, des origines au XVe siècle, París, Picard, 1986.

Barrios García, Ángel, Martín Expósito, Alberto, "Demografía medieval: modelos de poblamiento en la Extremadura castellana a mediados del siglo XIII", Studia histórica. Historia medieval, 1 (1983), págs. 113-148.

Bouhier, Abel, Galicia. Ensaio xeográfico de análisis e interpretación de un vello complexo agrario, Santiago de Compostela, Xunta de Galicia, 2001.

Cores Trasmonte, Baldomero, Sociología Rural de Galicia, A Coruña, Librigal, 1973.

Durany Castrillo, Mercedes, "Organización social del espacio berciano (siglos IX-XIII)", en José Ángel Sesma Muñoz, Carlos Laliena Corbera (coords.), La pervivencia del concepto: nuevas reflexiones sobre la ordenación social del espacio en la Edad Media, Zaragoza, Universidad de Zaragoza, 2008, págs. 149-196.

Duro Peña, Emilio, El monasterio de San Pedro de Rocas y su colección documental, Orense, Instituto de Estudios Orensanos "Padre Feijoo", 1972. 
Duro Peña, Emilio, El monasterio de San Esteban de Ribas de Sil, Orense, Instituto de Estudios Orensanos "Padre Feijoo", 1977.

Enríquez Rodríguez, Flora (coord.), Pantón. A rota do Románico na Ribeira Sacra, Santiago de Compostela, Agencia Gráfica Gallega, 2002.

Fariña Jamardo, Xosé, El hábitat gallego, La Coruña, Diputación provincial de La Coruña, 1981.

Fariña Tojo, José, Los asentamientos rurales en Galicia, Madrid, Instituto de Estudios de Administración Local, 1980.

Fernández de Oviedo y Vieites, José Ignacio, Colección diplomática del monasterio de Santa María de Ferreira de Pantón, Lugo, Diputación provincial de Lugo, 1994.

Flórez, Henrique, España Sagrada. Theatro geographico-historico de la iglesia de España, Madrid, Oficina de Pedro Marín, 1789.

Fossier, Robert, Historia del campesinado en el Occidente Medieval, Barcelona, Crítica, 1985.

García Álvarez, Manuel Rubén, Galicia y los gallegos en la Alta Edad Media. Demografía 1, Santiago de Compostela, Pico Sacro, 1975.

García de Cortázar, José Ángel, Del Cantábrico al Duero: trece estudios sobre organización social del espacio en los siglos VIII a XIII, Santander, Universidad de Cantabria, 1999.

García de Cortázar, José Ángel, La formación de la sociedad hispano-cristiana del Cantábrico al Ebro en los siglos VIII al XI. Planteamiento de una hipótesis y análisis del caso de Liébana, Asturias de Santillana, y Trasmiera. Santander, Ediciones de Librería Estudio, 1982.

García de Cortázar, José Ángel, La Historia rural medieval: un esquema de análisis estructural de sus contenidos a través del ejemplo hispanocristiano, Santander, Universidad de Santander, 1978.

García Pazos, Fernando (coord.), A parroquia en Galicia. Pasado, presente e futuro, Santiago de Compostela, Xunta de Galicia, 2009.

Isla Frez, Amancio, La sociedad gallega en la alta Edad Media, Madrid, CSIC, 1992.

López Alsina Fernando, La ciudad de Santiago de Compostela en la Alta Edad Media, Santiago de Compostela, Universidad de Santiago de Compostela, 1988.

López Carreira, Anselmo (ed.), O Condado de Lemos na Idade Media. I Simposio de Historia en Terra de Lemos, Ourense, Xunta de Galicia, 2008.

Lorenzo Fernández, Xoaquín, A casa, Vigo, Galaxia, 1982.

Loscertales de García de Valdeavellano, Pilar, Tumbos del Monasterio de Sobrado de los Monjes, Madrid, Dirección General del Patrimonio Artístico y Cultural, Archivo Histórico Nacional, 1976.

Lucas Álvarez, Manuel y Lucas Álvarez, Pedro, El monasterio de San Clodio do Ribeiro en la Edad Media: estudio y documentos, Sada (A Coruña), Edicios do Castro, 1996.

Lucas Álvarez, Manuel y Lucas Álvarez, Pedro, El priorato benedictino de San Vicenzo de Pombeiro y su colección diplomática en la Edad Media, A Coruña, Edicios do Castro, 1996.

Llano Cabado, Pedro de, Arquitectura popular en Galicia: razón e construcción, Santiago de Compostela, Colexio Oficial de Arquitectos de Galicia, Comisión de Cultura, 1989.

Mariño Veiras, Dolores, Señorio de Santa María de Meira (De 1150 a 1525). Espacio rural, régimen de propiedad y régimen de explotación en la Galicia medieval, La Coruña, Ediciones Nos, 1983. 
Marques, André Evangelista, O casal: uma unidade de organização social do espaço no Entre-Douro-e-Lima (906-1200), Noia (A Coruña), Toxosoutos, 2008.

Marques, André Evangelista, Da representação documental à materialidade do espaço. Território da diocese de Braga (séculos IX-XI), Porto, CITCEM, Edições Afrontamento, 2014.

Martínez-Burgos García, Palma, Vizuete Mendoza, José Carlos (coords.), Religiosidad popular y modelos de identidad en España y América, Cuenca, Universidad de Castilla-La Mancha, 2000.

Méndez Pérez, José; Otero Piñeyro Maseda, Pablo S.; Romaní Martínez, Miguel, El monasterio de San Salvador de Chantada (siglos XI-XVI): historia y documentos, Santiago de Compostela, CSIC, 2016 (Anejos de Cuadernos de Estudios Gallegos, 40).

Niemeier, Georg, "Tipos de población rural en Galicia”, Estudios geográficos, vol. 6, 19 (1945), págs. 301-327.

Otero Pedrayo, Ramón, Historia de Galiza, Buenos Aires, Ediciones Nos, 1962.

Pallares, María Carmen, Portela, Ermelindo, “Aproximación al estudio de las explotaciones agrarias en Galicia en los siglos IX-XII" en Actas de las primeras jornadas de metodología aplicada a las ciencias históricas. Historia medieval (1973), Santiago de Compostela, Universidad de Santiago de Compostela, 1975, págs. 93-113.

Pallares, María Carmen, Portela, Ermelindo, "De la villa del siglo IX a la aldea del siglo XIII: Espacio agrario y feudalización en Galicia”, Asturiensia medievalia, 8 (1995-1996), págs. 47-69.

Pallares, María Carmen, Portela, Ermelindo, El Bajo Valle del Miño en los siglos XII y XIII. Economía agraria y estructura social, Santiago de Compostela, Universidad de Santiago, 1971.

Pallares, María Carmen, Portela, Ermelindo, "La villa, por dentro. Testimonios galaicos de los siglos X y XI", Studia historica. Historia medieval, 16 (1998), págs. 13-43.

Pallares Méndez, María Carmen, El monasterio de Sobrado: un ejemplo de protagonismo monástico en la Galicia medieval, A Coruña, Diputación Provincial de A Coruña, 1975.

Pallares Méndez, María Carmen, "El poblamiento rural gallego en la Edad Media", Obradoiro: revista de arquitectura y urbanismo, 2 (1978), págs. 3-14.

Pastor de Togneri, Reyna (coord.), Poder monástico y grupos domésticos en la Galicia foral (siglos XIII-XV). La casa. La comunidad, Madrid, CSIC, 1990.

Pazo Labrador, Alberto José, "Notas para el estudio de los asentamientos rurales en Galicia" en Actas do Simposio Internacional Otero Pedrayo e a Xeografía de Galicia, A Coruña, 1989, págs. 149-180.

Pereira Ferreiro, Sara, "El monasterio de Santa María de Xunqueira de Espadañedo y su colección diplomática", Boletín Auriense, 9 (1979), págs. 151-230.

Portela Silva, Ermelindo, "La propiedad, el trabajo y los frutos de la tierra en la Galicia Medieval (900-1300)", Liceo Franciscano, 31 (1978), págs. 157-200.

Portela Silva, Ermelindo, La Región del obispado de Tuy en los siglos XII a XV. Una sociedad en la expansión y en la crisis, Santiago de Compostela, El Eco Franciscano, 1976.

Portela Silva, María Xosé, Documentos da catedral de Lugo. Século XV, Santiago de Compostela, Consello da Cultura Galega, Ponencia de Patrimonio Histórico, 1998.

Portela Silva, María Xosé, Documentos da catedral de Lugo. Século XIV, Santiago de Compostela, Consello da Cultura Galega, Ponencia de Patrimonio Histórico, 2007. 
Pounds, Norman J.G., La vida cotidiana: Historia de la cultura material, Barcelona, Crítica, 1992.

Precedo Ledo, Andrés José, Galicia, estructura del territorio y organización comarcal, Santiago de Compostela, Xunta de Galicia, 1987.

Reboreda Morillo, Susana (coord.), Homenaxe á profesora Lola F. Ferro: estudios de historia, arte e xeografia, Ourense, Universidade de Vigo, 2005.

Ríos Rodríguez, María Luz, "El casal medieval gallego: contribución al estudio de una unidad de poblamiento y explotación (siglos XI al XIII)", El Museo de Pontevedra, 43 (1989), págs. 109-128.

Rodríguez, Ana (ed.), El lugar del campesino en torno a la obra de Reyna Pastor, Valencia, CSIC, 2007.

Rodríguez Castelao, Alfonso Daniel, Sempre en Galiza, Buenos Aires, Edición “As Burgas”, 1961.

Rodríguez Fernández, Carlos, La colección diplomática de San Vicente del Pino, Tesis doctoral, Universidad de Granada, Granada, 1991.

Rodríguez Mínguez, Luis, Pantón. Patrimonio y termalismo, Santiago de Compostela, Ribeira Sacra lucense, 2007.

Rodríguez Muñiz, Víctor, O Mosteiro de Santa Cristina de Ribas de Sil na Idade Media, Ourense, Museo Arqueolóxico Provincial de Ourense, 2010.

Romaní Martínez, Miguel, et alii, Colección diplomática do mosteiro cisterciense de Sta. María de Oseira (Ourense) 1310-1399, Santiago de Compostela, Tórculo Edicións, 1989.

Saavedra, Pegerto, Sobrado Correa, Hortensio, Presedo Garazo, Antonio, "La red parroquial y el clero rural en la Galicia de los siglos XVI-XIX: resultados de una investigación en curso", Obradoiro de historia moderna, 22 (2003), págs. 93-128.

Sáez, Emilio, Sáez, Carlos, Colección diplomática del monasterio de Celanova (842-1230), Alcalá de Henares, Universidad de Alcalá, 1996.

Salas Auséns, José Antonio, "Cuando las fuentes nos engañan: fogajes, vecindarios y demografía (ss. XIV-XVIII)", Aragón en la Edad Media, 20 (2008), págs. 691-708.

Sampaio, Alberto, As "villas" do norte de Portugal: estudo sobre as origens e estabelecimento da propriedade, Oporto, Imprensa Moderna, 1903.

Sánchez Albornoz, Claudio, Despoblación y repoblación del valle del Duero, Buenos Aires, Instituto de Historia de España, 1966.

Sánchez Belda, Luis, Documentos reales de la Edad Media referentes a Galicia, Servicio de publicaciones del ministerio de educación nacional, Madrid, 1953.

Sánchez Carrera, María del Carmen, El Bajo Miño en el siglo XV. El espacio y los hombres, A Coruña, Fundación "Pedro Barrié de la Maza", 1997.

Sánchez Pardo, José Carlos, "Bases para el análisis geohistórico del poblamiento rural tradicional en Galicia”, Boletín de la Asociación de Geógrafos Españoles, 62 (2003), págs. 75-99.

Sánchez Pardo, José Carlos, "Las iglesias rurales y su papel en la articulación territorial de la Galicia medieval (ss. VI-XII): un caso de estudio", Melanges de la Casa de Velázquez, 40 (2010), págs. 149-170. 
Sánchez Pardo, José Carlos, Territorio y poblamiento en Galicia entre la antigüedad y la plena Edad Media, Tesis doctoral, Universidade de Santiago de Compostela, Santiago de Compostela, 2008.

Sánchez Pardo, José Carlos, "Una propuesta de análisis geohistórico de las aldeas tradicionales gallegas”, Cuadernos de estudios gallegos, 120 (2007), págs. 103-134.

Souto González, Xosé María, "Encol do habitat e do poboamento: o caso de Galicia", Cuadernos de Estudios Gallegos, 98 (1982), págs. 7-63.

Vaquero Díaz, María Beatriz, Colección diplomática do Mosteiro de San Salvador de Celanova (Ss. XIII-XV), Santiago de Compostela, Tórculo, 2004. 